Revista lus et Praxis, Año 25, № 3, 2019, pp. 19 - 68

ISSN 0717 - 2877

Universidad de Talca - Facultad de Ciencias Jurídicas y Sociales

El derecho de opción del acreedor ante el incumplimiento contractual en el

Derecho de remedios europeo

Rodrigo Barcia Lehmann - José Maximiliano Rivera Restrepo

Trabajo recibido el 8 de junio de 2017 y aprobado el 15 de agosto de 2019

\title{
El derecho de opción del acreedor ante el incumplimiento contractual en el Derecho de remedios europeo
}

\author{
THE OPTION OF THE CREDITOR BEFORE THE BREACH OF \\ CONTRACT IN THE EUROPEAN ReMEDIES LAW
}

\author{
RODRIGO BARCIA LeHMANN* \\ José Maximiliano Rivera Restrepo**
}

ResUMEN

En el trabajo que se presenta se pretende analizar, desde la perspectiva del análisis económico del Derecho, el llamado derecho de opción del acreedor, particularmente en la regulación que ofrece el Código Europeo de Contratos y los Principios de Derecho Europeo de los Contratos.

ABSTRACT

In the work presented, it is intended to analyze from the perspective of the economic analysis of the law, the so-called right of option of the creditor, particularly in the regulation offered by the European Code of Contracts and the European Contract Law Principles

Palabras Clave

Opción, análisis económico del Derecho, contratos, resolución, principios Lando.

KEYWORDS

Option, economic analysis of law, contracts, resolution, Lando Principles.

\section{Introducción}

El presente trabajo pretende discutir los criterios de determinación del derecho de opción para el acreedor dentro de lo que se denomina el Derecho

\footnotetext{
* Es licenciado en Ciencias Jurídicas y Sociales, Universidad Central de Chile, 1991; MBA Economía y Dirección Internacional de Empresas, MEDI, Universidad Autónoma de Madrid, 1997; European Master in Law and Economics, Complutense und Hamburg Universität, 1998; doctor en Derecho Privado. Dirección postal: Pedro de Valdivia № 1509, Providencia, Santiago de Chile, Código Postal: 7501015. E-mail: rbarcia@uft.cl

** Inició sus estudios en el Instituto Nacional y en la Facultad de Filosofía y Humanidades de la Universidad de Chile. Abogado de la Universidad de Chile y magíster en Derecho, con mención en Derecho Privado por la Universidad de Chile. Máster universitario en Derecho Privado por la Universidad Complutense de Madrid. Doctor en Derecho Civil por la Universidad Complutense de Madrid. Notario Público, Conservador de Bienes Raíces, de Comercio, Minas y Archivero Judicial Suplente de Tocopilla. Profesor de Derecho Civil en la Universidad San Sebastián. Dirección postal: Recoleta No 7, Piso 7, Recoleta, Santiago de Chile, Código Postal: 8420524. E-mail: jrivera_lex@hotmail.com
} 
de remedios. En la primera parte se hace una evaluación de los criterios que el propio soft law e instrumentos internacionales determinan a dicho efecto, para, en la segunda parte, hacer un breve análisis económico de los referidos criterios, que nos permitirá evaluar el derecho de remedios. Para poder realizar esta evaluación desde el análisis económico del Derecho $(A E D)$, se recurrirá a las expectativas rotas del acreedor, que serán determinadas conforme al quiebre eficiente del contrato, y al rechazo al cumplimiento forzado, como remedio preferente, por regla general, para luego realizar un análisis de los costos de transacción y las externalidades que el derecho de remedios entendido por el soft law puede generar. El objeto de estudio, por tanto, es el denominado derecho europeo de remedios, el que será contrastado con el análisis económico del Derecho.

\section{El derecho de opción en el derecho europeo de remedios como criterio de exigibilidad, por una parte, y de razonabilidad, buena fe y eficiencia, por la otra}

\section{Regulación del Anteproyecto de Código Europeo}

El Anteproyecto de Código Europeo de los Contratos propone una serie de remedios para el caso de incumplimiento contractual: (i) la suspensión del cumplimiento (art. 108); (ii) la concesión de un plazo de gracia y plazos especiales (art. 110); (iii) la reducción del precio (art. 113); (iv) el cumplimiento específico (art. 111); (v) la restitución de las especies dadas o entregadas (arts. 115 y 160); (vi) la declaración de daño sufrido (art. 171); (vii) la indemnización de daños y perjuicios (art. 111); (viii) las acciones inhibitoria y conminatoria (art. 172); (ix) la resolución (arts. 114 y 158); (x) la renegociación del contrato por efecto de la cláusula rebus sic stantibus (art. 157); (xi) la cláusula penal (art. 170); (xii) la cláusula de exoneración (art. 106), y (xiii) el arbitraje (art. 173). Lo importante es que estos remedios no son incompatibles entre sí, salvo que, acumulados, sobrepasen los perjuicios experimentados por el acreedor o deriven en una situación insostenible ${ }^{1}$ para el deudor ${ }^{2}$.

En cuanto al derecho de remedios, el Anteproyecto de Código Europeo exige que se trate de un incumplimiento de importancia o relevante. En efecto, el artículo 107 ("incumplimiento grave") ${ }^{3}$ del Anteproyecto dispone : "1. Según se establece a continuación, el incumplimiento es grave si se refiere a una de las

\footnotetext{
1 De Castro (2003), p. 637.

${ }^{2}$ Vattier (2008), pp. 433-444.

3 Yzquierdo (2003), p. 435.
} 
obligaciones principales (y no secundarias) del contrato, y, además, cuando, teniendo en cuenta la cualidad de las personas y la naturaleza de la prestación, el incumplimiento suponga para el acreedor un perjuicio tal que le prive sustancialmente de lo que jurídicamente puede esperarse del contrato. 2. Se considerará, en particular, que el incumplimiento es grave cuando éste: a) es total; b) es parcial, pero ha desaparecido objetivamente el interés del acreedor de obtener el resto ${ }^{4}$. 3. Las obligaciones secundarias son aquellas cuyo cumplimiento es de escasa importancia, en atención a la economía de la relación contractual y al interés del acreedor" ${ }^{\prime \prime}$. En este punto, el Anteproyecto siguió a la Convención de Viena sobre Compraventa Internacional de Mercaderías, de 1980 (CISG), particularmente en su artículo 25, que dispone: "El incumplimiento del contrato por una de las partes será esencial cuando cause a la otra parte un perjuicio tal que la prive sustancialmente de lo que tenía derecho a esperar en virtud del contrato, salvo que la parte que haya incumplido no hubiera previsto tal resultado y que una persona razonable de la misma condición no lo hubiera previsto en igual situación $n^{\prime \prime}$. El Anteproyecto establece que estamos frente a un incumplimiento relevante cuando es total o cuando, siendo parcial, el interés del acreedor en obtener el resto haya desaparecido objetivamente ${ }^{7}$. Ahora bien, las prestaciones secundarias son aquellas que no presentan una relevancia menor para la economía del negocio y para el interés del acreedor ${ }^{8}$.

En general, la doctrina ha dicho que el Anteproyecto ha seguido al sistema alemán del "nachfrist" ${ }^{\text {, }}$ que fue también establecido por la Convención de Viena sobre Compraventa Internacional de Mercaderías ${ }^{10}$. En efecto, el artículo 114 de dicho texto dispone que "1. Si se produce un incumplimiento grave, en el sentido del art. 107, el acreedor tendrá derecho a exigir la resolución del contrato, requiriendo al deudor el cumplimiento en un plazo razonable que no sea inferior a quince días, y notificándole que, transcurrido inútilmente el plazo, el contrato se considerará resuelto. 2. Si el contrato incluye una cláusula en virtud de la cual el incumplimiento de determinada prestación por una de las partes atribuye a la otra parte el derecho a resolver el contrato, el incumplimiento se considerará, en todo caso, grave en el sentido del art. 107, y el

\footnotetext{
4 YzQuierdo (2003), pp. 435-436.

5 García (s/f), p. 52.

6 UNIDROIT (2010), p. 18.

7 García (2012), pp. 37-74.

8 Academia de Pavia (2009), pp. 25-26.

9 Miláns del Bosch (2012), p. 692.

10 Academia de Pavia (2009), p. 26.
} 
contrato se considerará resuelto desde el momento en que la parte interesada notifique al deudor que quiere hacer uso de la cláusula en cuestión. 3. Una vez transcurrido el plazo indicado en el primer apartado del presente artículo, o si el deudor ha recibido la notificación mencionada en el segundo apartado del presente artículo, el acreedor no puede exigir el cumplimiento del contrato, pudiendo rechazarlo, y el deudor no está obligado a cumplir. El acreedor puede además ejercitar los derechos indicados en los arts. 115 y 116. $4^{11}$. La resolución del contrato también puede ser parcial en aquellos casos en que, aunque el deudor no haya cumplido la totalidad de la obligación, el acreedor acepte la parte recibida, ejercitando el derecho a pagar un precio proporcionalmente inferior como se prevé en los arts. 92 y 93. 5. Si el incumplimiento se produce durante la ejecución de un contrato de cumplimiento continuo o periódico, el efecto de la resolución no afecta a las prestaciones cumplidas con anterioridad ${ }^{12}$. 6. El acreedor no tiene derecho a resolver el contrato si el cumplimiento depende exclusivamente de una acción u omisión que le sea imputable, a reserva de la facultad de aplicar los arts. 103 y 104. Tampoco tendrá este derecho si ha hecho creer a la otra parte que no procedería a la resolución, aun tratándose de un incumplimiento grave"13. Es decir, en caso de incumplimiento de importancia relevante, el contratante cumplidor puede proceder a efectuar la resolución extrajudicial, requiriendo al contratante incumplidor para que, dentro de un plazo, que no puede ser inferior a 15 días, cumpla con su obligación. En caso que transcurra este término, el contrato quedará resuelto ipso iure, salvo que los contratantes hubieren convenido una cláusula resolutoria ${ }^{14}$. Esta resolución unilateral puede ser sometida a la revisión judicial, pudiendo el tribunal: (i) confirmarla, ordenando la restitución conforme a los arts. 162 y siguientes; (ii) negarla, por no cumplirse las condiciones de la misma; (iii) otorgarle al deudor una prórroga del plazo de cumplimiento, o (iv) declarar la resolución parcial del contrato ${ }^{15}$. Es interesante que el Anteproyecto regule la resolución parcial del contrato. En este sentido, el artículo 77 ("Cumplimiento parcial") dispone que "1. El acreedor

\footnotetext{
11 VATTIER (2003), p. 433.

${ }^{12}$ En este sentido, Carrasco Perera señala que: "What does "non-performance» mean in general European Civil Codes did not give any answer to this question because most of them did not know a general expression to integrate all sorts of failure of contractual obligations. According to the comments from the European Commission, some academic European lawyers have raised a "particular concern about remedies for breach", as a subject matter in which the multiplicity of national rules creates problems for the internal market". CARRASCO (2003), p. 301.

13 García (s/f), pp. 55-56.

14 Academia de PaVia (2009), p. 26.

15 Poveda (2003), pp. 593-594.
} 
puede rehusar el cumplimiento parcial, aunque la prestación sea divisible, salvo que el contrato, la ley o los usos dispongan otra cosa. 2. Sin embargo, si la deuda se compone de una parte líquida y de otra ilíquida, el deudor podrá realizar, y el acreedor exigir, el pago de la primera en los términos previstos en el contrato o en el presente Código ${ }^{16}$, sin esperar a que la segunda sea líquida" ${ }^{17}$. También proceden los Ilamados remedios suspensivos, aun cuando el incumplimiento no tenga el carácter de relevante ${ }^{18}$. Estos son: (a) el cumplimiento forzado de la obligación (art. 111); (b) la reparación de los defectos de la cosa entregada o, en su defecto, el reemplazo de la misma (art. 112); (c) la acción estimatoria o quanti minoris (art. 113). En cambio, cuando se trata de un incumplimiento relevante, sólo proceden los remedios resolutorios (art. 114) ${ }^{19}$.

En cuanto al incumplimiento anticipado ${ }^{20}$, el Código Europeo de Contratos, en sus artículos 90 y 91, decreta que el incumplimiento puede verificarse cuando el deudor manifiesta su voluntad en orden a incumplir su deber y cuando el deudor no se halla en situación de poder cumplir ${ }^{21}$. En este sentido, el artículo 90 ["Deudor que declara por escrito no querer cumplir"] dispone lo siguiente: "1. Si el deudor declara por escrito al acreedor no tener intención de cumplir, este último tiene la facultad de notificarle por escrito y sin demora, y en todo caso dentro de ocho días, que en virtud de esta declaración considera la obligación incumplida. En defecto de dicha notificación, el acreedor no podrá rechazar el cumplimiento que tenga lugar posteriormente. 2. El deudor, dentro de los ocho días siguientes a la recepción de la notificación mencionada en el apartado anterior, puede impugnarla por escrito; y si, en los ocho días que siguen, el acreedor no reconsidera por escrito su posición, deberá el deudor dirigirse al juez competente en un nuevo plazo de treinta días. En caso de inacción del deudor, el incumplimiento se considerará definitivo. 3. Salvo pacto en contrario entre las partes, los plazos indicados en los apartados anteriores y en los artículos siguientes se suspenden en los periodos festivos y vacacionales habituales y conforme a lo previsto en el art. $58^{\prime \prime 22}$.

La jurisprudencia española ha dado acogida a la noción de incumplimiento anticipado. Así, se puede citar la STS de 4 de febrero de 1997 (RJ/1997/675),

\footnotetext{
16 Poveda (2003), pp. 593-594.

17 García (s/f), p. 37.

18 Poveda (2003), p. 595.

19 YzQuierdo (2003), p. 436.

20 García (2012), p. 11.

21 YZquierdo (2003), p. 436.

22 García (s/f), pp. 44-45.
} 
que decreta la resolución de la obligación por incumplimiento del constructor; se probó el retraso en la ejecución de las obras, de tal forma que se dedujo que no es cierto que se cumplirá en el plazo previsto $^{23}$. En este sentido, el art. 109 establece que "1. Salvo lo previsto en el art. 101, el acreedor tiene derecho a rechazar el cumplimiento que se le ofrece o que se realiza antes del vencimiento convenido, o en cantidad superior a la debida, siempre que su rechazo no sea contrario a la buena fe en el sentido previsto en el artículo anterior, en la medida en que sea aplicable. 2. El acreedor tiene, en todo caso, el derecho de rechazar el cumplimiento que se le ofrece o se realiza después del vencimiento de un término pactado como esencial"24. Por su parte, el art. 91 ["Deudor que no se halla en situación de cumplir"] dispone que "1. Si antes del vencimiento del plazo, resulta razonable estimar que el deudor no está o no se ha situado en condiciones de cumplir una obligación contractual, o que no se encuentra en situación de cumplirla sin defectos notables, y que todo ello no es debido a una acción u omisión del acreedor, este último puede instarle por escrito a que, en un plazo razonable, que no será inferior a quince días, garantice adecuadamente el cumplimiento futuro con la advertencia de que a falta de garantía el incumplimiento se considerará definitivo. 2. El deudor, si no proporciona la garantía requerida, puede, en el plazo de ocho días, impugnar por escrito a la solicitud del acreedor y debe, si este último no reconsidera por escrito su posición en un plazo ulterior de ocho días, dirigirse al juez en un nuevo plazo de treinta días. En caso de inacción del deudor, el incumplimiento se considerará definitivo"25. Por otra parte, el art. 108 ["Derecho del acreedor a suspender el cumplimiento de los contratos sinalagmáticos"] dispone que "1. En los contratos sinalagmáticos, si una de las partes incumple o no ofrece cumplir su obligación, cualquiera que sea la gravedad del incumplimiento, el acreedor tiene la facultad de suspender la prestación debida por él simultánea o sucesivamente, salvo que tal suspensión sea contraria a la buena fe. 2. Se considera como contrario a la buena fe la suspensión: a) que ocasione a la otra parte consecuencias excesivamente onerosas; b) cuando, a pesar de que se haya comprobado que el incumplimiento es de escasa entidad, la suspensión conlleve la extinción de la obligación del acreedor; c) que perjudique un derecho fundamental de la persona" 26 .

\footnotetext{
23 Andreu (2003), p. 337.

24 García (s/f), pp. 52-53.

25 García (s/f), pp. 44-45.

26 García (s/f), p. 52.
} 
Por lo que se refiere al cumplimiento específico"27, el art. 111 dispone: "1. Si el deudor todavía no ha cumplido la obligación, cualquiera que sea la importancia del incumplimiento, el acreedor tiene derecho a exigir el cumplimiento o a que lo complete en forma específica si es objetivamente posible $y$, en todo caso, a reserva de daños y perjuicios ${ }^{28}$. 2. En particular, el acreedor puede solicitar al juez: a) la entrega de cosa cierta y determinada o las cosas genéricas que se le deban, cuando el deudor las tenga en su poder o las haya transmitido a un tercero de mala fe o por un acto simulado; b) la autorización para obtener, en la medida de lo posible, y a costa del deudor, la cosa cierta y determinada o las cosas genéricas que se le deban, que estén en poder de terceros; c) que el deudor sea condenado a cumplir su obligación, en la medida de lo posible, o a completar la prestación debida. También puede obtener la autorización del juez de cumplir o completar él mismo la obligación o de hacerla cumplir o completar por terceros, a costa del deudor; d) que el deudor sea condenado a destruir lo que ha realizado incumpliendo una obligación de no hacer. También puede obtener la autorización del juez de destruir por sí mismo o de hacer destruir por terceros, a costa del deudor, lo que ha realizado éste incumpliendo una obligación de no hacer; e) una sentencia que produzca el efecto jurídico del contrato que el deudor se había comprometido a celebrar mediante un contrato preliminar incumplido. 3. Para estimular al deudor incumplidor a cumplir la condena para asegurar en forma específica el cumplimiento de la prestación que es objetivamente posible, el juez puede además condenar al deudor, si incumple o cumple con retraso, al pago de una multa cuya cuantía no excederá el triple del valor de la prestación debida, y que corresponderá en la proporción del $70 \%$ al acreedor y del 30\% al Estado. Tal multa puede consistir en una suma fija que genere intereses en la medida fijada por el juez, o en una suma debida por cada día de retraso, que se repartirá en las proporciones indicadas" ${ }^{29}$.

El Anteproyecto de Código Civil Europeo de Contratos consagra también el derecho de sustitución y reparación, establecido en el art. 112, que reza: "1. Si el deudor no cumple la obligación total o parcialmente, el acreedor tiene el derecho, a reserva de daños y perjuicios, de obtener, en la medida en que esto sea objetivamente o subjetivamente posible, que el deudor: a) le entregue una cosa diferente sobre la que puede disponer libremente, o efectúe una prestación

\footnotetext{
$27 \operatorname{VatTier}(\mathrm{s} / \mathrm{f})$, p. 434.

${ }^{28}$ En este sentido, YZQuierdo Tolsada señala que "La acción de cumplimiento específico se basa en el hecho objetivo del incumplimiento: la obligación subsiste, y subsiste insatisfecha, pues la imposibilidad de prestar se ha debido a hecho imputable al deudor (o éste se encontraba en mora)", YzQUIERDO (2003), p. 442 .

29 García (s/f), pp. 53-54.
} 
diferente-y que por ello el interés del acreedor se realice de manera satisfactoriamediante el pago ulterior de una suma o la eventual restitución de una parte de la suma entregada que, en caso de desacuerdo, será fijada por el juez en el caso en que la cosa o la prestación diferentes tengan mayor o menor valor; b) provea las reparaciones que son necesarias para eliminar los defectos o imperfecciones de la cosa entregada o de la obra efectuada; c) provea, en caso de que los problemas nazcan con la puesta en funcionamiento o la utilización de la cosa entregada debido a una imperfección de la misma, a su instalación, funcionamiento o envío de técnicos que expliquen la utilización y, eventualmente, que se encarguen durante un cierto tiempo del mantenimiento necesario para un buen uso. 2. El acreedor puede, además, ser autorizado por el juez para realizar las reparaciones necesarias él mismo o por terceros, a costa del deudor. 3. El acreedor que pretenda ejercitar los derechos antes indicados debe notificarlo inmediatamente al deudor desde el momento que descubra los defectos. 4. Antes de que el acreedor haya enviado la notificación a que se refiere el apartado anterior al deudor, este, notificándolo al acreedor, podrá sustituir o eliminar los defectos o completar la entrega, a su costa" ${ }^{\prime 30}$. En virtud del art. 112, entonces, el contratante cumplidor tiene la facultad, en caso de incumplimiento contractual, de solicitar la entrega de una prestación diferente, sin perjuicio de la indemnización de daños y perjuicios que pueda pedir. La doctrina ha señalado que en esta norma se debió decir derechamente que la prestación del equivalente es un cumplimiento verdadero, y no una indemnización de perjuicios ${ }^{31}$.

En cuanto al remedio de la reducción del precio, el artículo 113 establece que "1. El acreedor que acepte la entrega de cosa diferente de valor inferior, o con imperfecciones, o un conjunto de cosas de valor inferior al debido, o una prestación de hacer diferente a la convenida o con imperfecciones, tendrá derecho, notificándolo en tiempo útil al deudor, a pagar un precio inferior al convenido. Podrá, en su caso, exigir la restitución de parte de la suma entregada, en la proporción fijada por el juez en defecto de acuerdo. 2. Si la prestación ofrecida o efectuada tiene un valor superior al debido, se aplicarán las reglas del art. 101" 32 .

Por último, en cuanto al remedio de la indemnización de daños y perjuicios, el art. 116 dispone lo siguiente: "1. A reserva de lo previsto en los artículos precedentes, en caso de incumplimiento y cualquiera que sea la gravedad, el acreedor tiene derecho a obtener del deudor la indemnización de los daños causados, tal y como se prevén en los arts. 162 y ss. 2. Tal derecho puede ejercitarse acumulativamente

30 García (s/f), p. 54.

31 YZQuierdo (2003), pp. 441-442.

32 García (s/f), p. 55. 
con los previstos en los preceptos precedentes, según lo previsto en éstos y en el art. $171^{\prime \prime 33}$. Por lo tanto, la indemnización de daños y perjuicios siempre procede, al margen de los remedios suspensivos o resolutorios ${ }^{34}$. Es decir, en virtud de esta norma, se dispone la obligación de indemnizar los daños y perjuicios, en el caso de incumplimiento total, cumplimiento inexacto o retraso en el cumplimiento, a menos que exista una causa extraña, ajena a la voluntad del deudor, de carácter imprevisible e irresistible (art. 162.1), o en las prestaciones profesionales, el deudor acredite que cumplió diligentemente con su labor (art. 162.3), debiendo en todo caso el acreedor probar la existencia y cuantía del daño o perjuicio (art. 162.7). La indemnización comprende tanto el daño emergente como el lucro cesante (art. 163.1) y el daño moral o no patrimonial (art. 164) $)^{35}$.

Cuando existe incumplimiento contractual, el deudor deberá indemnizar los daños y perjuicios razonables causados al acreedor ${ }^{36}$. El acreedor deberá probar los daños provocados; por ello, se dice que la indemnización de daños y perjuicios no es un remedio automático, sino hipotético o eventual ${ }^{37}$. El deudor puede acreditar que los daños obedecen a una conducta extraña a la voluntad del deudor, o bien si acredita haber adoptado la debida diligencia en el cumplimiento de su profesión u oficio, respondiendo únicamente de la culpa grave o lata cuando hubiera actuado con el consentimiento del afectado, sus representantes, personas cercanas a él o su asistente legal, que hubieran sido informados (art. 162, apartados $1^{\circ}$ y $\left.3^{\circ}\right)^{38}$.

En los Unidroit se agrega el criterio de la subsidiariedad para la determinación de la procedencia de los remedios, que se aplica conforme a la razonabilidad y la buena fe (art. 7.2.5 Unidroit).

\section{Regulación específica del derecho de remedios en los Principles of European Contract Law}

En general, la doctrina plantea que no resulta extraño que la Comisión Lando no haya acogido el sistema alemán en materia de incumplimiento contractual, que presenta como gran desventaja el ser un sistema elaborado sobre la base del concepto de "imposibilidad", a partir del cual se enuncian y desarrollan

\footnotetext{
33 García (s/f), p. 56.

34 YZquierdo (2003), p. 436.

35 JIMÉNEZ (2009), pp. 429-430.

36 ViCENTE (2003), pp. 601-617.

37 YZquierdo (2003), p. 443.

38 Vattier (2003), p. 435.
} 
una serie de supuestos ${ }^{39}$. Este sistema, de raigambre romana, fue elaborado por Mommsen, en el s. XIX, a partir de la stipulatio romana ("obligationes stricti iruis"). Por el contrario, el Derecho moderno se remonta a los contratos consensuales, como la compraventa, que se estructuraron sobre la base del principio de la buena fe y en el intercambio. La cuestión más importante era establecer bajo qué criterios la indemnización de daños y perjuicios podía ser atribuida al contratante incumplidor, cuestión que el Code francés basa en un concepto unitario de inejecución. En cambio, tanto en el common law como en los sistemas jurídicos escandinavos existe una proposición que abarca todas las formas de incumplimiento ("non-performance").

A partir de Rabel, que incorporó esta noción al Derecho de la compraventa de La Haya de 1964 y luego a la Convención de Viena de 1980 sobre Compraventa Internacional de Mercaderías. Esta noción se generaliza en los Principios Unidroit, los PECL y en algunas legislaciones europeas. Este concepto básico se denomina "Pflichtverleztung" en el Proyecto de la Comisión de Reforma del Derecho de Obligaciones en Alemania que daría lugar a la reforma del $B G B$ y "non-performance" en los Principios Unidroit y en los PECL ${ }^{40}$. Este concepto, según Zimmermann, "[e]ngloba supuestos de (en la terminología alemana) imposibilidad, mora, lesión del derecho de crédito y la garantía por defectos en la cosa entregada" ${ }^{\prime 1}$ (lo destacado entre paréntesis es nuestro). La pregunta que surge a continuación es cuál es el criterio a partir del cual se califica el incumplimiento contractual. Bajo la opinión clásica ${ }^{42}$, se dice que es la culpa o negligencia del deudor la que lo determina. Así, la indemnización de daños y perjuicios no opera cuando el daño se deriva de una situación ajena a la voluntad del deudor o que este no pudo razonablemente prever al tiempo de celebrar el contrato ${ }^{43}$.

\footnotetext{
39 MÖsLein (2010), pp. 669 y ss.

40 Zimmermann (2000), pp. 122-123.

41 ZimMermanN (2000), pp. 122-123.

${ }^{42}$ El § 276 del BGB dispone que: "(1) Der Schuldner hat Vorsatz und Fahrlässigkeit zu vertreten, wenn eine strengere oder mildere Haftung weder bestimmt noch aus dem sonstigen Inhalt des Schuldverhältnisses, insbesondere aus der Übernahme einer Garantie oder eines Beschffungsrisikos, zu entnehmen ist. Die Vorschriften der $\S \S 827$ und 828 finden entsprechende Anwendung. (2) Fahrlässig handelt, wer die im Verkehr erforderliche Sorgfalt außer Acht lässt. (3) Die Haftung wegen Vorsatzes kann dem Schuldner nicht im Voraus erlassen werden". Por su parte, el $\$ 278$ del BGB señala que "Der Schuldner hat ein Verschulden seines gesetzlichen Vertreters und der Personen, deren er sich zur Erfüllung seiner Verbindlichkeit bedient, in gleichem Umfang zu vertreten wie eigenes Verschulden. Die Vorschrift des $\& 276$ Abs. 3 findet keine Anwendung". BASSENGE et al. (2002), pp. 340 y 348, respectivamente.

${ }^{43}$ Este es el sistema consagrado en el Code francés, en los artículos 1147 y 1148 . El primer artículo dispone que "Le débiteur est condamné, s'il y a lieu, aun payement de dommages et intérêts, soit à
} 
En los PECL, como se verá, el contratante cumplidor dispone de cinco remedios: (1) el cumplimiento forzoso; (2) la resolución del contrato; (3) la suspensión de cumplimiento de su prestación; (4) la indemnización de daños y perjuicios, y (5) la reducción del precio. En cambio, si el incumplimiento se encuentra justificado, declinan la indemnización de perjuicios y el cumplimiento ${ }^{44}$. Se debe señalar que el acreedor puede optar por cualquiera de estos cinco remedios. Así lo establece el artículo 8:101 ["Medios de protección del crédito"]: "(1) Siempre que una parte no cumpla con alguna de las obligaciones derivadas del contrato y el incumplimiento no pueda justificarse con arreglo al artículo 8:108, el perjudicado puede recurrir a cualquiera de los medios dispuestos en el capítulo 9. (2) Cuando el incumplimiento de una de las partes pueda justificarse con arreglo al artículo 8:108, el perjudicado puede recurrir a cualquiera de los medios dispuestos en el capítulo 9, excepto la pretensión de cumplimiento y la indemnización por daños y perjuicios. (3) La parte no puede recurrir a los medios dispuestos en el capítulo 9 en la medida en que haya provocado el incumplimiento de la otra parte" ${ }^{45}$.

\subsection{Derecho a exigir el cumplimiento}

En general, la doctrina ha señalado que los $P E C L$, siguiendo la tradición del Derecho continental, otorgan una pretensión de cumplimiento ("specific performance $\left.{ }^{\prime \prime}\right)^{46}$ al contratante cumplidor, tanto en las obligaciones dinerarias como en otra clase de obligaciones ${ }^{47}$. La tendencia en esta materia es utilizar el specific performance de forma excepcional, reemplazándolo por la

raison de l'inexécution de l'obligation, soit à raison du retard dans l'exécution, toutes les fois qu'il ne justie pas que l'inexécution provient d'une cause étrangère qui ne peut lui être imputée, encore qu'il n'y ait aucune mauvaise foi de sa part". Por su parte, el art. 1148 señala lo siguiente: "Il n'y a lieu à aucuns dommages et intérêts lorsque, par suite d'une forcé majeure ou d'un cas fortuit, le débiteur a été empêché de donner ou de faire ce à quoi il était obligé, ou a fait ce qui lui était interdit", TISSERANDMARTIN, et al. (2012), pp. 1354 y 1393, respectivamente.

44 Zimmermann (2000), p. 125.

45 Unidroit (2010), p. 1; Comisión de Derecho Europeo de los Contratos (2000), p. 28.

46 Marsal y Lauroba (2003), pp. 459-469.

${ }^{47}$ En este sentido, Whittaker señala que "[...] By contrast, the remedy of specific performance has a series of very different attributes [respecto de la "termination»]. White it is up to an injured party to elect to apply for it, it is by its nature a judicial remedy, and the court has a general and «equitable» discretion as to whether or not it should be awarded (though this discretion is to an extent structured by the existence of principles)". WHITTAKER (2006), p. 47. 
indemnización de daños y perjuicios como regla general ${ }^{48}$. El common law sigue esta directriz ${ }^{49}$, pues, se ha desarrollado a partir de la "action of assumpsit"

Respecto de las obligaciones dinerarias, el artículo 9:101 ["Obligaciones pecuniarias" $]^{51}$ dispone que "(1) El acreedor tiene derecho a percibir el dinero que se le debe. (2) Cuando el acreedor todavía no haya cumplido su obligación y resulte claro que el deudor se negará a aceptar su prestación, el acreedor, pese a todo, puede llevar a cabo dicha prestación y cobrar lo que se le deba según el contrato salvo que: (a) Hubiera podido hacer un negocio sustitutivo razonable sin excesivo esfuerzo o coste. (b) O no fuera razonable llevar a cabo su prestación conforme a las circunstancias" ${ }^{\prime \prime 2}$. El fundamento de esta norma parece ser, cuestión que resulta casi obvia, el pacta sunt servanda, en cuya virtud el contratante cumplidor tiene la facultad para exigir la realización de la prestación por el deudor ${ }^{53}$. Esta facultad aparece también en el Marco Común de Referencia (cuyo acrónimo es MCR en castellano o CFR, según la versión inglesa: Commun Frame of Reference $)^{54}$, en sus arts. III.-3:301 como regla general y IV B.-6:103 en relación con el contrato de arrendamiento ${ }^{55}$. De la lectura de esta norma se puede colegir claramente que el cumplimiento está excluido en dos hipótesis: (i) El cumplimiento irrazonable. En este escenario, según la doctrina, se trata del caso en que la ejecución de la prestación resulta irrazonable. La Comisión nos da un ejemplo: cuando el deudor, antes de que se inicie el cumplimiento, manifiesta su intención de no interesarle la ejecución de la prestación. Así, puede ocurrir tal situación en los contratos de construcción o en los de larga duración ${ }^{56}$. Esta norma tiene su antecedente en el Derecho consuetudinario inglés y en la tradición irlandesa y escocesa. El problema se presentaba cuando un contratante, en forma anticipada, le había manifestado a su contraparte que ya no le era necesaria la prestación y, no obstante este aviso, el otro contratante había continuado con la ejecución de la misma (casos White v. Carter (Councils) Ltd. McGregor de 1962; Attica Sea Carriers Corp. v.

48 JiMÉneZ (2009), pp. 420-421.

49 Solución adoptada por los sistemas jurídicos sudafricano y escocés ("specific implement"), entre otros. ZIMMERMANN (2000), p. 127.

50 Zimmermann (2000), p. 126.

51 Ramos (2012), p. 111.

52 Comisión de Derecho Europeo de los Contratos (2000), p. 30.

53 Lando y Beale (2003), p. 576.

${ }^{54}$ En este sentido, véase: Arroyo y Amayuelas (2003), pp. 639-663; Schulze (2003), pp. 629-637.

55 JIMÉNEZ (2009), p. 421.

${ }^{56}$ Lando y Beale (2003), p. 577. 
Ferrostaal Poseidon Bulk Reederei GmbH de 1976, y Salaried Staff London Loan Co. Ltd. v. Swears \& Wells Ltd. de 1985). En el primer caso, la Corte razonó que el contratante culpable tiene la carga de acreditar que el inocente no presenta un legítimo interés en la ejecución de la prestación ${ }^{57}$. Se agrega que esta excepción es extraña al Derecho continental europeo. La única situación semejante se presenta en el Derecho belga, pues el art. 1794 del Código Civil belga exige al acreedor, en ciertos casos, resolver el contrato ${ }^{58}$; por ejemplo, en el contrato de construcción ${ }^{59}$. (ii) En el caso de los negocios sustitutivos ${ }^{60}$. Tal situación acontece cuando el acreedor puede efectuar un negocio sustitutivo, en ese evento tiene que resolver el contrato (no pudiendo exigir la contraprestación del deudor) y proceder a efectuar un negocio sustitutivo de conformidad con el art. 9:506, o bien reclamar una indemnización por daños y perjuicios (art. 9:507 $P E C L)^{61}$. Es curioso que, por una parte, el acreedor no pueda reclamar el dinero que le adeuda el otro contratante y, por la otra, esté facultado para solicitar una indemnización de daños y perjuicios, pero esto es así en el common law. Esta situación, para el civil law, parece ser un contrasentido, pues la indemnización tiene por finalidad reemplazar al objeto de la prestación (indemnización compensatoria) o la oportunidad en que debió ejecutarse el pago (indemnización moratoria). Aquí pareciera ser que estaría reemplazando al primero. Por su parte, el artículo 9:102 [“Obligaciones no pecuniarias"] ${ }^{62}$ expresa lo siguiente: "(1) La parte perjudicada tiene derecho a reclamar el cumplimiento en forma específica de las obligaciones no pecuniarias y a la reparación del cumplimiento defectuoso de las mismas. (2) Sin embargo, el cumplimiento en forma específica no podrá obtenerse cuando: (a) El cumplimiento resulte ilícito o imposible. (b) Dicho cumplimiento fuera a provocar en el deudor esfuerzos o gastos irrazonables $^{63}$. (c) El cumplimiento consista en una prestación de servicios u obra de carácter personal o se base en una relación personal. (d) $O$ el perjudicado pueda obtener de manera razonable la prestación por otras vías. (3) La parte perjudicada perderá su derecho a la pretensión de cumplimiento específico si

\footnotetext{
57 LANDO y Beale (2003), pp. 578-579.

${ }^{58}$ En este sentido, la doctrina señala que "Las leyes sueca y finlandesa (Sale of Goods) $\$ 52$ disponen que, cuando el vendedor debe procurar o producir expresamente para el comprador las mercaderías, si el comprador resuelve el contrato, el vendedor no puede llevar a cabo la prestación y reclamar el precio. El vendedor sólo podrá reclamar daños, incluido el lucro cesante". LANDO y BeALE (2003), p. 579.

59 Lando y Beale (2003), p. 579.

${ }^{60}$ En este caso, al igual que en el anterior, "[...] el deudor corre el riesgo de tener que cargar con una prestación que ya no le interesa". LANDO y BeALE (2003), p. 577.

${ }^{61}$ Lando y Beale (2003), p. 576.

62 Zimmermann (2000), p. 128.

${ }^{63}$ Marsal y Lauroba (2003), pp. 462-463.
} 
no lo ejerce en un tiempo prudencial desde que haya sabido o hubiera debido saber que se había producido un incumplimiento" ${ }^{64}$. Esta norma se refiere a las obligaciones no pecuniarias y para ello se utiliza la expresión "cumplimiento específico" ${ }^{65}$ o "ejecución in natura" ("specific performance $\left.{ }^{1}\right)^{66}$, pues no existe otra expresión mejor para referirse a esta situación. En este caso, el contratante cumplidor tiene la facultad para exigirle el cumplimiento al deudor y, además, para requerir auxilio del órgano jurisdiccional a fin de que se obligue al deudor incumplidor a ejecutar la prestación debida ${ }^{67}$. Esta facultad fue muy discutida por la Comisión, pues, una vez más, se enfrentaba el common law (sólo considera a esta facultad como una excepción) con el civil law (en este sistema se autoriza de forma general al acreedor a exigir esta facultad). La limitación en el cumplimiento específico presenta una serie de beneficios: (a) se satisface de mejor manera los intereses del acreedor; (b) se soslaya la determinación del monto de una posible indemnización de daños y perjuicios, y (c) se robustece la relación entre las partes, con el fin de que vuelvan a contratar en el futuro ${ }^{68}$.

\subsection{Excepciones al cumplimiento específico}

Según lo dispuesto por el art. 9:102 (2) PECL, son cuatro las excepciones: (a) Cuando el cumplimiento resultare ilícito o imposible. Esta excepción resulta evidente, pues no se podría compeler al deudor a ejecutar una prestación imposible o ilícita. En el caso de las imposibilidades temporales, se suspenderá el cumplimiento mientras dure el obstáculo. (b) Cuando dicho cumplimiento fuera a provocar en el deudor esfuerzos o gastos irrazonables ${ }^{69}$. Es interesante esta excepción, aun cuando ella arrastra una cierta indefinición o ambigüedad, pues se trata de un concepto abierto a interpretación (determinar en qué caso el esfuerzo o gasto es desproporcionado ${ }^{70}$. Esta norma no se refiere a los hechos

\footnotetext{
64 UNIDROIT (2010), pp. 30-31.

65 Marsal y Lauroba (2003), pp. 461-462.

66 Miláns del Bosch (2012), p. 693.

${ }^{67}$ Lando y Beale (2003), p. 580.

68 Lando y Beale (2003), p. 581.

69 Los Principios de Derecho Contractual Europeo nos entregan un ejemplo para ilustrar esta situación: "A ha vendido su yate "Eliza» a $B$ y le ha prometido que se lo librará en su domicilio (de B). Durante el viaje, "Eliza» sufre un accidente con otro barco y el yate se hunde a 200 metros de profundidad. Los gastos de rescate del yate supondrían cuarenta veces su valor. Exigir que A cumpla con su obligación de entrega sería desproporcionado". LANDO y BEALE (2003), p. 583.

70 La noción de "cumplimiento irrazonable" se encuentra lo suficientemente extendida entre los países nórdicos (Finlandia y Suecia), Alemania, Italia, Grecia, Bélgica, Francia, Irlanda, Austria, Portugal, entre otros. Lando y BeALE (2003), pp. 589-590.
} 
imprevisibles que surjan con posterioridad a la celebración del negocio (cláusula rebus sic stantibus), pues ésta se encuentra recogida en el art. 6:111, siendo ésta una norma especial, que prevalece por sobre aquélla ${ }^{71}$. (c) Cuando el cumplimiento consista en una prestación de servicios u obra de carácter personal o se base en una relación personal. Esta excepción es doble, pues se acogen dos casos: (i) en el caso de las obras personales y (ii) cuando el cumplimiento se basa en una relación personal. Éstas se excluyen porque: (1) de obligar el juez a ejecutar una obra personal a la parte que ha decidido no hacerlo, estaría interfiriendo con su ámbito de libertad; (2) si se obligara a la parte deudora a ejecutar la obra o el servicio personal, podría ésta ejecutarlo de una manera no conveniente, lesionando así las expectativas del acreedor, y (3) al tribunal se le impondría una carga difícil de realizar (el seguimiento del estricto cumplimiento de la prestación en los términos debidos) ${ }^{72}$. Por último, el art. 9:102 (3) establece que la parte perjudicada perderá su derecho a la pretensión de cumplimiento específico si no lo ejerce en un tiempo prudencial desde que haya sabido o hubiera debido saber que se había producido un incumplimiento ${ }^{73}$. En este sentido, la determinación de la duración de un plazo razonable o prudencial dependerá de las circunstancias y la prueba del mismo estará a cargo del deudor. En fin, en estas hipótesis, el acreedor no puede reclamar el cumplimiento específico de la prestación, pero sí una indemnización de daños y perjuicios (art. 9:103 $)^{74}$.

\subsection{Suspensión del cumplimiento (exceptio non adimpletu contractus o excepción de incumplimiento) ${ }^{75}$}

El artículo 9:201 ["Derecho a suspender la ejecución de la prestación"] establece que "(1) La parte que deba cumplir su obligación al mismo tiempo que la otra parte o después de ella, podrá suspender la ejecución de su prestación hasta que la otra parte haya ofrecido el cumplimiento de su obligación o la haya cumplido efectivamente. La primera parte puede suspender total o parcialmente el cumplimiento de su obligación, según lo que resulte razonable conforme a

\footnotetext{
71 San Miguel (2003), p. 371.

72 Lando y Beale (2003), pp. 582-584.

73 En este sentido, los Principios de Derecho Contractual Europeo establecen que "El art. 9:102 (3) adopta el principio del common law de que la parte perjudicada que se retrasa de manera irrazonable en reclamar el cumplimiento in natura puede perder su demanda. En el $\$ 23$ de la Sale of Goods Act finlandesa y sueca se encuentra una regla similar". LANDO y BEALE (2003), p. 591.

74 Lando y Beale (2003), p. 586.

75 En este sentido, expresa ZIMMERMAnN lo siguiente: "[Los PECL perpetúan] la tradición de la exceptio non adimpleti contractus". Zimmermann (2000), p. 126; Miláns del BosCh (2012), pp. 693-694.
} 
las circunstancias. (2) Igualmente, una parte podrá suspender el cumplimiento de su obligación tan pronto como resulte claro que la otra parte no cumplirá su obligación cuando llegue el vencimiento de la misma"76. En esta norma se consagra la exceptio non adimpleti contractus, ampliamente recogida en los diversos ordenamientos ${ }^{77}$, dándosele el nombre de "derecho a suspender la ejecución de la prestación" ${ }^{\prime \prime 8}$. Conforme a esta excepción, el cumplimiento de la prestación puede "suspenderse" mientras la contraparte no haya cumplido. Esta excepción tiene un efecto "paralizante" de la pretensión del actor en los contratos sinalagmáticos (se incluyen también los contratos multilaterales) ${ }^{79}$. En este caso, no es necesario que el incumplimiento sea esencial, a diferencia de lo que ocurre en el sistema del common law ${ }^{30}$, en el cual el incumplimiento debe ser relevante para autorizar a la contraparte a suspender la ejecución de su prestación, o bien cuando sea el propio contrato el que, de forma explícita o implícita, condicione el cumplimiento de la prestación al cumplimiento de la prestación de la contraparte ${ }^{81}$. En otro caso, la parte perjudicada tiene que cumplir con su obligación, sin perjuicio de tener la facultad para solicitar una indemnización de daños y perjuicios, si es que procede (breach of contract) ${ }^{82}$.

\footnotetext{
${ }^{76}$ UNIDROIT (2010), p. 31.

77 En este sentido, la doctrina señala que consagran esta excepción los siguientes cuerpos legales: "[...] BGB alemán § 320, CC griego art. 374, CC italiano art. 1460 (1), BW neerlandés art. 6:52 y CC portugués art. 428. En Francia, Bélgica, Luxemburgo, Austria, España y Dinamarca, los tribunales han reconocido esta norma como un principio general basado en disposiciones especiales y en el espíritu de la ley: v. para la compraventa, CC francés, belga y luxemburgués, arts. 1653, 1707 y (probablemente) 1612 y 1613; respecto al reconocimiento de la norma como un principio general en la jurisprudencia belga, Cass. 26 abril 1945, Pas. I; 24 abril 1947, R.C.J.B. 1949, 125; 12 septiembre 1973, Arr. Cass. 1974, 36. Para Austria v. ABGB §§ 1052, 1062 y Jabornegg; en España, art. 1466 CC y la literatura citada en el anterior apartado 1(a). para Dinamarca, v. Ussing, Alm. Del. 79". Lando y Beale (2003), p. 599.

${ }^{78}$ Lando y Beale (2003), p. 594.

79 Lando y Beale (2003), pp. 594-595.

${ }^{80}$ En este sentido, la doctrina señala que "La sección 28 de la Sale of Goods Act 1979 del Reino Unido, establece que salvo pacto en contrario, la entrega de las mercancías y el pago del precio son condiciones simultáneas (concurrentes en el tiempo), lo que implica que el vendedor ha de estar preparado y dispuesto a entregar la posesión de los bienes al comprador a cambio del precio y el comprador ha de estar preparado y dispuesto a pagar el precio a cambio de la posesión de las mercancías o bienes. La Sale of Goods Act 1983 irlandesa, s. 28 prevé lo mismo". Lando y Beale (2003), p. 598.

81 En el Derecho escocés, la reciprocidad (mutualidad) del contrato autoriza suspender el cumplimiento de la prestación frente a un incumplimiento (breach) de la contraria, mientras subsista un vínculo entre ella (caso Bank of East Asia v. Scottish Enterprise, 18 de enero de 1996). Lando y Beale (2003), pp. 582-584.

${ }^{82}$ Lando y Beale (2003), pp. 595-596.
} 


\subsection{Resolución del contrato}

En general, la doctrina señala que la tradición del civil law, estructurada a partir del Derecho romano, responde de forma imprecisa y poco clara en esta materia. Pues, en Roma, frente al incumplimiento contractual se establecían una serie de acciones, sin disponer de una norma general que agrupara todos los casos de incumplimiento del contrato, dado el carácter casuístico y fragmentario de este Derecho. Además de lo anterior, el legislador francés, al establecer como dogma el "pacta sunt servanda", titubeó a la hora de implantar una excepción general al mismo (la resolución). Por ello es que, a partir de la facultad resolutoria tácita, la doctrina comenzó a gestar una teoría general en torno a la resolución por incumplimiento, sobre la base de la opción que le entregaba la ley: o cumplimiento forzado de la obligación o resolución de la misma; en ambos casos, con indemnización de daños y perjuicios (art. 1124 Code) ${ }^{83}$.

A diferencia de lo anterior, los PECL siguen la tendencia moderna: la resolución procede con prescindencia de si el incumplimiento ${ }^{84}$ se encuentra o no justificado, siempre que éste tenga un carácter de relevancia suficiente ${ }^{85}$. Los PECL se refieren a la resolución del contrato en la Secc. 3, que se enmarca dentro del Capítulo 9 ["Recursos específicos en caso de incumplimiento"] ${ }^{86}$, particularmente en el artículo 9:301 ["Derecho a resolver el contrato"] ${ }^{87}$, que dispone: "(1) Una parte puede resolver el contrato si existe un incumplimiento esencial de la otra parte. (2) En caso de demora, la parte perjudicada también puede resolver el contrato conforme al artículo 8:106"88. Lo primero que llama la atención de esta disposición es que, una vez verificado el incumplimiento,

83 ZimMERMANN (2000), pp. 133 y 134.

84 De Priego (2012), p. 219.

85 En este sentido, como se vio, tanto la ConvenCIÓn de VIENA de 1980 como los Principios Unidroit hacen alusión a la relevancia que debe tener el incumplimiento para justificar la resolución. Así, los arts. 49.1 a) y 64.1 a) de la Convención hablan de "incumplimiento esencial". Por su parte, el art. 7.3.1. (1) de los PrinCIPIOs también se refiere a este concepto. Cnudmi (2011), pp. 15 y 20; UnIDrOIT (2010), p. 24.

${ }^{86}$ La resolución se regula entre los artículos 9:301 y 9:309; con todo, todo el Capítulo 9 se refiere a los recursos específicos en caso de incumplimiento. LANDO y BEALE (2003), pp. 575 y ss.

87 García (2012), pp. 21-22.

88 LANDO Y BeAle (2003), p. 601. 
en los términos exigidos por la norma, no se le puede otorgar ningún plazo de gracia al deudor ${ }^{89}$ para que cumpla su deber ${ }^{90}$.

$\mathrm{Al}$ "incumplimiento esencial"91 se refiere el artículo 8:103 de los PECL, en los siguientes términos: "El incumplimiento de una obligación es esencial para el contrato: (a) Cuando la observancia estricta de la obligación forma parte de la causa del contrato. (b) Cuando el incumplimiento prive sustancialmente a la parte perjudicada de sus justas expectativas respecto al contrato, salvo que la otra parte no hubiera previsto o no hubiera podido prever en buena lógica ese resultado. (c) O cuando el incumplimiento es intencionado y da motivos a la parte perjudicada para entender que más adelante ya no cabe contar con el cumplimiento de la otra parte" ${ }^{\prime \prime 2}$.

En este sentido, los PECL (art. 9:301) 93 $^{3}$ y la CISG (art. 49.1) requieren que la falta de conformidad tenga el carácter de esencial, para que proceda el remedio de la resolución del contrato ("rücktrittrecht") ${ }^{94}$.

En caso de que una parte incumpla con su deber, y dicho incumplimiento tenga el carácter de esencial, resulta evidente que el afectado puede deducir la acción resolutoria. El origen de esta disposición en el common law ${ }^{95}$ está particularmente en la figura de la "repudiation", o "anticipary repudiation" (caso Hochster v. De la Tour), como una forma de incumplimiento contractual in anticipando ${ }^{96}$. Esta noción de "incumplimiento previsible" no tiene cabida

\footnotetext{
${ }^{89}$ A diferencia de la Convención de Viena de 1980, que sí le confiere tanto al comprador como al vendedor la posibilidad de conceder, unilateralmente, un término de gracia. GARRO y ZUPPI (1990), pp. 177-181; Lando y BeAle (2003), p. 602.

90 En este sentido, se debe comparar la norma en comento con "[...] el délai de grâce francés y belga (CC art. 1184); de manera similar el CC español, art. 1124. (3), o, en los ordenamientos del common law, la regulación específica de protección en caso de decomiso (por ejemplo, en determinadas ocasiones el arrendatario puede ser protegido contra el decomiso por falta de pago de la renta: $v$. Treitel Remedies $\S 247$ ". Lando y Beale (2003), p. 601. Asimismo, se ha dicho que "Si se dan los requisitos del artículo 9:301, los presentes principios no han previsto que los órganos judiciales o un tribunal arbitral puedan conceder a la parte que hubiera incumplido período de gracia alguno". LANDO y BeALE (2003), p. 602.

91 En este sentido, ZIMMERMANN señala que "Esta idea [incumplimiento esencial] proviene básicamente del derecho inglés sobre incumplimiento y se remonta a la fértil concepción de Lord Mansfield a fines del siglo XVIII sobre una «implied condition» y a la distinción entre "warranties» $y$ "Conditions»". ZIMMERMANN (2000), pp. 133-134.

92 Lando y Beale (2003), p. 533.

93 Association Henri Capitant des Amis de la Culture Juridique Française (2008), p. 690.

94 SChulze (2009), p. 56.

95 En este sentido, la doctrina plantea que "El origen de esta disposición lo encontramos en el common law [...] y corresponde al Derecho escocés". LaNdo y BeALE (2003), p. 615.
}

96 Zimmermann (2000), p. 125. 
en el Derecho francés, español y portugués ${ }^{97}$. El fundamento de la exigencia de un incumplimiento esencial, según la doctrina, es que la resolución del contrato normalmente supone una serie de desventajas para el contratante incumplidor. Además, existen remedios más benignos, como la indemnización de daños y perjuicios y la reducción del precio, que no son tan categóricos como la resolución. Es decir, la resolución por incumplimiento operaría como ultima ratio, atendida las graves consecuencias que supone ${ }^{98}$. Todo lo anterior implica que sólo aquel incumplimiento que revista cierta gravedad (que sea esencial) será apto para resolver el contrato ${ }^{99}$. Ello se justifica, además, en el principio del pacta sunt servanda o en el principio de conservación de los contratos ${ }^{100}$. Cuando existe un incumplimiento esencial, la parte perjudicada puede, a su arbitrio, realizar cualquiera de las tres cosas siguientes: (a) negarse a aceptar una oferta de cumplimiento tardío (artículo 8:104 PECL) ${ }^{101}$; (b) exigir una garantía del correcto cumplimiento de la prestación debida (art. 8:105 PECL) ${ }^{102}$, o (c) poner fin al contrato ${ }^{103}$ (arts. 9:301, 9:302 y 9:304) ${ }^{104}$. Más aún, puede

97 Lando y Beale (2003), pp. 616-617.

98 Miláns del Bosch (2012), p. 694.

99 Lando y Beale (2003), p. 602.

100 Miláns del Bosch (2012), p. 694.

101 El artículo 8:104 de los PECL dispone que "A party whose tender of performance is not accepted by the other party because it does not conform to the contract may make a new and conforming tender where the time for performance has not yet arrived or the delay would not be such as to constitute a fundamental non-performance". LANDO y BEALE (2003), p. 84.

102 El artículo 8:105 de los PECL señala lo siguiente: "(1) A party which reasonably believes that there will be a fundamental non-performance by the other party may demand adequate assurance of due performance and meanwhile may withhold performance of its own obligations so long as such reasonable belief continues. (2) Qhere this assurance is not provided within a reasonable time, the party demanding it may terminate the contract if it still reasonably believes that there will be a fundamental non-performance by the other party and gives notice of termination without delay". LANDO Y BEALE (2003), p. 84.

103 En este sentido, Andreau señala que "El artículo 9:304 de los Principios concede a una de las partes la facultad de "resolver» el contrato (to terminate the contract) en aquellos casos en que la otra parte no quiera o no pueda cumplir en la fecha pactada, y con los mismos efectos que un actual non-performance, entre ellos, la posibilidad de solicitar daños y perjuicios (damages)". ANDREAu (2003), p. 333.

104 Por último, el artículo 9:301 ("Right to Terminate the Contract") de los PECL señala lo siguiente: "(1) A party may terminate the contract if the other party's nonperformance is fundamental. (2) In the case of delay the aggrieved party may also terminate the contract under Article 8:106". Por su parte, el artículo 9:302 ("Contract to be Performed in Parts") dispone que: "If the contract is to be performed in separate parts and in relation to a part to which a counter-performance can be apportioned, there is a fundamental non-performance, the aggrieved party may exercise its right to terminate under this Section in relation to the part concerned. It may terminate the contract as a whole only if the nonperformance is fundamental to the contract as a whole". Por último, el artículo 9:304 ("Anticipatory 
igualmente resolver el contrato $^{105}$, con prescindencia de si el incumplimiento es o no esencial, cuando exista un plazo de cumplimiento y el contratante incumplidor ha incurrido en mora ${ }^{106}$. Asimismo, la resolución, en los PECL, no requiere de sentencia judicial declaratoria; es decir, se consagra el sistema alemán de la resolución unilateral ${ }^{107}$ o por notificación ("notice procedure $\left.{ }^{\prime \prime}\right)^{108}$. Incluso, la resolución se produce automáticamente, cuando el contratante incumplidor carece de un plazo adicional y en el caso en que el incumplimiento esté justificado, a causa de un obstáculo total y permanente para la realización de la prestación ${ }^{109}$.

La resolución, conforme al art. 9:303 PECL, requiere de una comunicación o aviso al deudor ${ }^{110}$. El afectado perderá su facultad de resolver si no la ejercita dentro de un plazo razonable y comunica esta situación dentro de un plazo razonable desde que tuvo noticia del incumplimiento o debió saber del mismo. Esta comunicación debe ser una manifestación expresa y directa de la voluntad del perjudicado, en orden a solicitar la resolución del contrato o rechazar la oferta de cumplimiento ${ }^{111}$. Con todo, existen dos casos en que no se requiere comunicación alguna para que se produzca la resolución: (i) cuando se le ha dado un plazo al deudor para que éste cumpla, comunicándosele que si, al vencimiento del mismo, no cumple, el contrato se resolverá automáticamente [art. 8:106 (3)]; (ii) cuando el incumplimiento se encuentre justificado por imposibilidad absoluta y total [art. 9:304 (4)] ${ }^{112}$. La comunicación, aviso o notificación debe otorgarse dentro de un plazo razonable o prudencial, contado desde la fecha del incumplimiento (desde que se tuvo noticia o se debía conocer). Pareciera ser que éste es el sistema que va a predominar en el futuro (frente al sistema francés de la resolución judicial), pues cada vez son más los ordenamientos jurídicos que lo acogen. Sólo a modo de ejemplo podemos mencionar los de los

Non-Performance") señala lo siguiente: "Where prior to the time performance by a party it is clear that there will be a fundamental non-performance by it the other party may terminate the contract". LANDO y BeAle (2003), pp. 86-87.

105 El artículo 9:301 ("Derecho a resolver el contrato") dispone en su № 2 que "(2) En caso de retraso, la parte perjudicada también puede resolver el contrato conforme al artículo 8:106". UNIDROIT (2010), p. 32.

106 Para Zimmermann, esta norma se inspiró en el § 326 del BGB. Zimmermann (2000), pp. 135-136.

107 Adame (2009), p. 46.

108 Lando y Beale (2003), p. 602.

109 ZimmermanN (2000), pp. 136-137.

110 La resolución unilateral o por comunicación se encuentran en los sistemas británico, danés, finés, holandés y escocés, entre otros. LANDo y BeALE (2003), p. 611.

111 Lando y Beale (2003), pp. 608-609.

112 Lando y Beale (2003), p. 610. 
siguientes países: Dinamarca, Suecia, Finlandia, Francia, Bélgica, Luxemburgo, Reino Unido, Portugal, Alemania, Grecia, Italia y España ${ }^{113}$.

En cuanto a los efectos de la resolución ${ }^{114}$, éstos son: (a) libera a los contratantes de sus obligaciones; (b) a diferencia del derecho francés, no opera con efecto retroactivo. Pues, de no reputarse con vida el negocio, el afectado podría verse privado de la indemnización de daños y perjuicios (principalmente en lo que atinge al lucro cesante). Así lo establece el art. 8:102, que dispone que la parte afectada no pierde el derecho a pedir una indemnización de daños y perjuicios, por ejercer otros derechos ${ }^{115}$. Que la resolución opera sin efecto retroactivo significa que las partes no tienen el deber de proceder a restituirse mutuamente las cosas que recibieron en virtud del contrato. En nuestra opinión, los PECL confunden la noción de "resolución" con la de "terminación" ("termination"), pues no solamente no hacen el distingo, sino que, además, igualmente le conceden acción de indemnización de perjuicios a la parte afectada, lo que equivaldría a la repetición de las cosas dadas (la diferencia es que se devuelve su valor en dinero) ${ }^{116}$. Con todo, si uno de los contratantes recibe una cosa antes de la resolución, ésta puede ser posteriormente repudiada por la parte que la recibió, cuando hubiere perdido sustancialmente su valor ${ }^{117}$; (c) en los contratos de ejecución fraccionada tiene aplicación el artículo 9:302 PECL, que dispone: "En un contrato de ejecución fraccionada, la parte perjudicada puede ejercer su facultad resolutoria, conforme a esta sección, sobre aquella parte del contrato que se hubiera incumplido de manera esencial y respecto de la que pueda determinarse el porcentaje de contraprestación a que afecta dicho incumplimiento ${ }^{118}$. El perjudicado únicamente podrá resolver ${ }^{119}$ el contrato en su totalidad si el incumplimiento resulta esencial para el conjunto del mismo"120; (d) para que surta efectos la resolución, salvo que se trate de la automática (cuando, conforme al artículo 8:108, una parte

113 Lando y Beale (2003), p. 612.

114 Al respecto, ROUILLER (2007), pp. 731-737.

115 Lando y Beale (2003), pp. 618-619.

116 Lando y Beale (2003), p. 629.

117 Zimmermann (2000), pp. 137-138.

118 La resolución respecto del contrato en su totalidad ("termination of the contract as a whole") sólo se refiere a las obligaciones futuras. LANDO y BeALE (2003), p. 606.

119 En este sentido, se ha dicho que "La noción de «resolver» una parte del contrato ("termination in relation to a part») es una expresión no demasiado afortunada para referirse a que si bien no se pone fin al contrato, se tiene la ventaja de poder aplicar las normas generales sobre la resolución (así como la obligación de comunicarlo conforme al art. 9:303). El art. 73 CISG presenta el mismo enfoque". LaNdo y BeAle (2003), p. 606.

120 UnIDROIT (2010), p. 32. 
queda liberada del cumplimiento de su obligación a consecuencia de un impedimento absoluto y definitivo, el contrato queda automáticamente resuelto, sin necesidad de comunicación alguna, desde el momento en que se produjo la imposibilidad), es necesaria una comunicación o aviso dirigido al deudor, dentro de un plazo razonable desde que haya sabido o hubiera debido saber que se había producido el incumplimiento, pues, de no cumplir con esta exigencia, la parte perjudicada por la resolución pierde su derecho (art. 9:303 PECL) ${ }^{121}$. Como se dijo, en ciertos casos procede la repetición de las cosas dadas o entregadas en virtud del contrato resuelto. Éstos son: (a) Bienes cuyo valor ha disminuido (art. 9:306). Aquí, uno de los contratantes recibió un bien que carece de valor si no se cumple el resto de las obligaciones; por ejemplo, una empresa celebra un contrato de arrendamiento con el fin de contar con un programa de contabilidad necesario para gestionar el negocio. La empresa recibe el hardware, pero no el software; por tanto, podría devolverle a la proveedora el primero, pues le es inútil sin el software. (b) La restitución de sumas de dinero. En este sentido, el art. 9:307 PECL dispone que: "En caso de resolución del contrato, las partes tienen derecho a recuperar el dinero que hubieran pagado por una prestación que no hayan recibido o que legítimamente se hubieran negado a aceptar"122. Esta disposición se aplica cuando uno de los contratantes ha adelantado dinero a la otra y luego se niega a aceptar la prestación de ésta, con los debidos intereses (art. 9:508) ${ }^{123}$, siempre que exista una causa justificada ${ }^{124}$; por ejemplo, una parte le adelanta el dinero a la contraparte para que construya diez casas $y$,

\footnotetext{
121 Agrega el art. 9:303 de los PECL que "[...] (3) (a) Si llegado el vencimiento de la obligación no ha habido ofrecimiento de pago, la parte perjudicada no necesita comunicar que resuelve el contrato antes de que se produzca un ofrecimiento en tal sentido. Si posteriormente se produce un ofrecimiento, la parte perjudicada perderá su facultad resolutoria si no ejercita su acción comunicándolo en un plazo razonable desde que haya tenido noticia del ofrecimiento o hubiera debido tenerla. (b) Sin embargo, si la parte perjudicada sabe o tiene motivos para saber que la otra parte todavía tiene intención de ofrecer el pago en un plazo razonable y así ocurre, aquélla perderá su derecho de resolución del contrato cuando sin motivo hubiera dejado de comunicar a la otra parte que ya no aceptaría el pago. (4) Si conforme al artículo 8:108 una parte queda liberada del cumplimiento de su obligación a consecuencia de un impedimento absoluto y definitivo, el contrato queda automáticamente resuelto, sin necesidad de comunicación alguna, desde el momento en que se produjo la imposibilidad". UNIDROIT (2010), p. 32.

122 Lando y Beale (2003), p. 621.

123 En este sentido, Jiménez MUÑoz señala que "Tanto los PECL y RPECL y el DCFR como los Principios Unidroit se pronuncian en el mismo sentido, estableciendo el devengo de intereses moratorios por el impago de una cantidad de dinero desde el momento del incumplimiento hasta el del pago, y concretan el tipo de interés moratorio en el tipo medio a corto plazo aplicado por los bancos comerciales a los grandes clientes en operaciones, para la moneda de pago convenida y en el lugar en que deba procederse al pago, criterio éste que parece el más ajustado a las exigencias del comercio internacional [...]", JIMÉNEZ (2009), p. 423.

124 En este sentido, véase: Marsal y Lauroba (2003), pp. 464 y ss.
} 
luego de haber construido tres de ellas, se resuelve el contrato. La primera tiene la facultad de exigir la restitución del dinero que adelantó por las casas que no se construyeron $^{125}$. (c) Restitución de bienes distintos del dinero (art. 9:308). En este caso, una parte entregó a la contraria ciertos bienes, diversos del dinero, y la contraparte incumplió con su obligación; la primera está autorizada para solicitar la repetición de dichos bienes, siempre que no se lesionen los derechos de terceros ${ }^{126}$ (en este caso, deberá devolver el valor de dichos bienes) ${ }^{127}$.

Por último, el art. 9:309 establece que "En caso de resolución del contrato, la parte que haya llevado a cabo una prestación que no pueda devolverse y por la que no hubiera recibido pago o contraprestación alguna, tiene derecho a recibir un importe razonable acorde con el valor que la prestación haya tenido para la otra parte"128. En este escenario, se trata de beneficios o ganancias que no es posible devolver, en cuyo caso debe procederse a repetir el valor de los mismos, salvo que la utilidad o ganancia no alcance a cubrir los costos que fueron asumidas por ella ${ }^{129}$.

\subsection{Daños y perjuicios}

El art. 9:501 de los PECL ("[Derecho a la indemnización de daños y perjuicios]") dispone que "(1) La parte perjudicada tiene derecho a una indemnización de daños y perjuicios respecto de las pérdidas sufridas a consecuencia del incumplimiento de la otra parte, siempre que este incumplimiento no quede cubierto por la excepción del artículo 8:108. (2) Las pérdidas que cubre esta indemnización incluyen: (a) Pérdidas no pecuniarias y (b) Futuras pérdidas previsibles y probables" ${ }^{\prime 130}$. El primer comentario que merece este artículo es algo obvio: debe existir un daño para que proceda la indemnización de daños y

\footnotetext{
${ }^{125}$ En el sistema del common law se establece que "[...] si la parte demandante ha cumplido su prestación o una parte divisible de la misma, sólo dispone de una acción para obtener el precio pactado. En el caso de un cumplimiento parcial, se distingue entre los casos de frustration (imposibilidad) y los casos de incumplimiento imputable (breach). Cuando un contrato resulta imposible (se «frustra»), de acuerdo con la Law Reform (Frustrated Contracts) Act 1943, s. 1 (3), el juez tiene el poder discrecional de conceder aquello que suponga una restitución en sentido estricto [...]". LaNDO y BeALE (2003), p. 633.

126 Puede ocurrir, en este caso, que, "[...] antes de la resolución, la parte que ha incumplido haya transmitido a su vez algunos bienes a la parte perjudicada. Si el perjudicado puede devolver su propiedad pero no lo hace, los tribunales pueden ordenar que se devuelvan dichos bienes o que se entregue el importe de su valor de acuerdo con el art. 9:308". Lando y BeAle (2003), p. 623.

127 Lando y Beale (2003), pp. 619-625.

128 Lando y Beale (2003), p. 625.

129 Lando y Beale (2003), pp. 625-626.

130 UNIDROIT (2010), p. 34.
} 
perjuicios $^{131}$. Este requisito es inherente a la indemnización tanto en el civil law como en el common law ${ }^{132}$, en el que los tribunales ingleses otorgan los "nominal damages"133. Estos eran, en el s. XIX, un "peg" (colgador) para las sentencias sobre costas. En la actualidad, el Código $\mathrm{M}^{\mathrm{C}}$ Gregor niega el derecho de solicitar una indemnización de daños y perjuicios a la parte que no ha experimentado un daño ${ }^{134}$ (art. 432 Código $\mathrm{M}^{c}$ Gregor) ${ }^{135}$. Es frecuente la inclusión de este remedio contractual en el sistema del common law, lo que se ha proyectado al ámbito de los contratos internacionales, erigiéndose como la principal solución frente al incumplimiento contractual ${ }^{136}$. Un aspecto importantísimo es que la indemnización de daños y perjuicios procede siempre que existan perjuicios ${ }^{137}$. Incluso procede con prescindencia de la culpa, a lo menos respecto de la imputabilidad dentro de la concepción clásica ${ }^{138}$, salvo que se trate de un incumplimiento justificado (art. 8:108 PECL) ${ }^{139}$, aplicándose a toda clase de incumplimiento ${ }^{140}$. En cuanto a los criterios para determinar el quantum de la indemnización de daños y perjuicios, hay que tener presente lo que reza el artículo 9:502 de los PECL: "[e]l cálculo de la indemnización de daños y perjuicios se hará de forma que se coloque al perjudicado en una posición lo más próxima posible a la que hubiera disfrutado de haberse ejecutado correctamente el contrato. La indemnización por daños

\footnotetext{
131 ROUILLER (2007), p. 758.

132 Lando y Beale (2003), p. 639.

133 Van Zelst (2008), pp. 118-152.

134 VAN ZeLST (2008), p. 132.

135 McGREGOR (1997), p. 112; ZimMermanN (2000), p. 128.

136 Miláns del Bosch (2012), p. 696; Vicente (2003), p. 601.

137 JIMÉNEZ (2009), p. 427.

138 Lando y Beale (2003), p. 623. En contrario, por ejemplo, el Derecho holandés (art. 6:98 del BW). LANDO Y BeALE (2003), p. 653.

139 El art. 8:108 de los PECL ("Exoneración por imposibilidad en el cumplimiento") dispone que "(1) Una parte queda liberada de su deber de cumplimiento si prueba que no puede proceder al cumplimiento de su obligación por un impedimento que queda fuera de su control y que no se puede pretender de manera razonable que hubiera debido tenerse en cuenta dicho impedimento en el momento de la conclusión del contrato o que la parte hubiera debido evitar o superar dicho impedimento o sus consecuencias. (2) Cuando el impedimento sea tan sólo temporal, la exoneración prevista en este artículo produce sus efectos durante el tiempo en el que persista el impedimento. Sin embargo, si el retraso se tradujera en un incumplimiento esencial, el acreedor puede tratarlo en tal sentido. (3) La parte que incumple debe asegurarse de que, en un plazo razonable desde que supo o hubiera debido enterarse de dichas circunstancias, la otra parte recibe una comunicación de la existencia del impedimento y de sus efectos sobre la capacidad de la parte para cumplir su obligación. La otra parte tiene derecho a una indemnización por daños y perjuicios por las pérdidas que pudieran resultar de no recibir esa comunicación". Comisión de Derecho Europeo de los Contratos (2000), pp. 29-30.
}

140 Lando y Beale (2003), p. 639. 
comprende las pérdidas efectivamente sufridas por la parte perjudicada ${ }^{141}$ y las ganancias que haya dejado de obtener ${ }^{\prime 142}$. La indemnización de daños y perjuicios contempla el daño patrimonial (daño emergente y lucro cesante) y el daño moral $^{143}$ o no patrimonial ${ }^{144}$. El contratante incumplidor solamente responderá por los daños que haya previsto o que hubiera podido razonablemente prever al tiempo de la celebración del contrato como una consecuencia lógica del incumplimiento ${ }^{145}$, salvo que el incumplimiento sea deliberado o gravemente negligente (art. 9:503 PECL) ${ }^{146}$. En este sentido, se ha dicho que esta regla es de origen inglés ("contemplation"). Esta regla fue creada en el caso Hadley v. Baxendale 147 de 1854 (por el Tribunal de Exchequer) y tuvo su antecedente en la obra de los franceses Dumoulin y Pothier ${ }^{148}$. En este sentido, varios ordenamientos jurídicos han limitado el monto de la indemnización por daños y perjuicios a aquello que hubiera previsto o debido prever al tiempo de celebrar el contrato, salvo que se trate de un incumplimiento deliberado o exista negligencia grave ${ }^{149}$. En este sentido, el common law, como se dijo más arriba, limita la indemnización a las pérdidas previsibles ${ }^{150}$. El monto de la indemnización disminuye en caso de que

${ }^{141}$ En el common law, a diferencia del civil law, procede la indemnización por incumplimientos de poca monta y aun cuando no hubiera pérdidas para la parte afectada. LANDO y BeAle (2003), p. 642.

142 Comisión de Derecho Europeo de los Contratos (2000), p. 34.

143 UnIDROIT (2010), p. 641.

${ }^{144}$ En cuanto al daño moral, Zimmermann señala que "La acción indemnizatoria comprende daños no patrimoniales. Esto se opone al § 253 BGB (una norma limitada por el supuesto especial de gran trascendencia práctica del § 651 f.II BGB), pero se corresponde con el derecho francés ("préjudice moral») y con el derecho inglés (en la medida que genera "pain and suffering» $O$ "inconvenience»)". ZiMMERMANN (2000), p. 129.

145 En este sentido, JIMÉNEZ MUÑOZ señala que "Esta regla de previsibilidad ya se recogía en la CISG (art. 74), y después en los Principios UNIDROIT (art. 7.4.4), pero también es tradicional tanto en el ámbito del common law como en los Derechos continentales de inspiración francesa; en cambio, la excepción de los supuestos de dolo (o culpa grave), en que se recupera la regla de la indemnización integral -que no aparece en la CISG y los Principios Unidroit-, se toma por los PECL (y RPECL) de los Derechos de inspiración francesa, siendo inexistente en la órbita del common law". JIMÉNEZ (2009), p. 428.

146 En este sentido, la doctrina señala que "Como regla general, los ordenamientos del common law no atienden al grado de culpa de la parte que incumple en lo que respecta a la indemnización por daños y perjuicios [...]". LANDO y Beale (2003), p. 654.

147 En este sentido, se ha dicho que "El test de previsibilidad también se dispone en el Derecho francés, belga y luxemburgués, v. art. 1150 CC. En Bélgica y Francia, este test de previsibilidad se aplica ampliamente: sólo se exige que la clase de daño que se pueda causar sea previsible; v. respectivamente Cass. 23 febrero 1928, Pas. 85 y Cass. Com. 1965, D. 1965, 449". Lando y Beale (2003), p. 652.

148 ZimMermann (2000), p. 129.

149 Miláns del Bosch (2012), p. 698.

150 Lando y Beale (2003), pp. 650-651. 
el lesionado hubiera contribuido al incumplimiento o a sus efectos (art. 9:504 $P E C L)^{151}$; en igual sentido se consagra la doctrina de la mitigación ${ }^{152}$.

El artículo 9:506 ["Negocio de reemplazo"] dispone que "[c]uando el perjudicado haya resuelto el contrato y haya celebrado un negocio de reemplazo en un tiempo y modo razonables, puede resarcirse de la diferencia entre el precio del contrato y el precio del negocio de reemplazo, así como de los daños debidos a cualquier otra pérdida, en la medida en que puedan indemnizarse con arreglo a esta sección"153. Por lo tanto, la parte afectada podrá elegir -en el caso en que se produzca un negocio sustituto- entre pedir la diferencia entre el precio del negocio y el precio del negocio sustituto ${ }^{154}$. Los PECL nos entregan un ejemplo: "S vende a B un coche Renault por un importe de 5.000 $£$, asegurándole que se trata de un modelo del año 1990. Se trata en realidad de un modelo del año 1988, cuyo valor en el mercado es de $1.500 £$ menos que el modelo de 1990. El precio pagado conforme al contrato no importa a la hora de calcular los daños. B tiene derecho a una indemnización por daños de 1.500 £, que constituye la diferencia de precio entre el valor garantizado del coche y el valor del coche que se entregó" 155 .

El artículo 9:508 PECL ["Retraso en el pago de una cantidad de dinero"] establece que "(1) Cuando se produzca un retraso en el pago de una cantidad de dinero, la parte perjudicada tiene derecho a los intereses devengados por esa suma desde el momento en que vencía la obligación hasta el momento efectivo del pago. Dichos intereses se calcularán conforme al tipo medio aplicado por los bancos comerciales a los grandes clientes en operaciones a corto plazo, para la moneda de pago convenida y en el lugar en que deba procederse al pago. (2) La parte perjudicada podrá resarcirse además de los daños debidos a cualquier otra pérdida, en la medida en que puedan indemnizarse con arreglo a esta sección"156. En este sentido, se ha dicho que el apartado $1^{\circ}$ establece un derecho de carácter general, para solicitar intereses en las obligaciones contractuales impagas. Los

151 Con ello, los PECL siguen al sistema alemán (§ 254 del BGB). Zimmermann (2000), p. 130.

152 El artículo 9:505 de los PECL ("Deber de mitigar el daño") establece que "(1) La parte que incumple no responde de las pérdidas sufridas por el perjudicado en la medida en que éste hubiera podido mitigar el daño adoptando medidas razonables. (2) El perjudicado tiene derecho a recuperar el importe de los gastos razonables que tuvo que hacer al intentar mitigar el daño". UNIDROIT (2010), p. 35.

153 UNIDROIT (2010), p. 35.

154 Lando y Beale (2003), p. 646.

155 Lando y Beale (2003), p. 646.

156 Unidroit (2010), p. 35. En este sentido, Zimmermann señala que "Por su parte, en el derecho inglés no existe una obligación general de pagar intereses, lo que se ha considerado insatisfactorio". ZIMMERMANN (2000), p. 131. 
intereses se tratan en forma independiente, y no en la norma que regula en general a la indemnización por daños y perjuicios, porque no es una indemnización ordinaria. El tipo de interés ${ }^{157}$ se establece conforme al promedio aplicado por los bancos comerciales a los grandes clientes en operaciones de corto plazo ${ }^{158}$. Por su parte, el apartado $2^{\circ}$ de esta norma extiende el remedio indemnizatorio no sólo a los intereses, sino que a otros daños y perjuicios adicionales; por ejemplo, la pérdida de una oportunidad de negocio que el afectado hubiera ejecutado con un tercero, siempre que el contratante incumplidor le hubiera pagado oportunamente el precio ${ }^{159}$.

Por último, el artículo 9:509 PECL se refiere a la indemnización pactada para el caso de incumplimiento ${ }^{160}$ (usualmente Ilamada en el Derecho continental "cláusula penal" ${ }^{161}$. En el escenario en que se hubiera estipulado una pena para el caso de incumplimiento de alguna de las partes, ésta deberá pagar la suma de dinero pactada al afectado, el que la recibirá con prescindencia de si sufrió o no un daño o perjuicio. La novedad es que dicha suma de dinero puede ser reducida a una cifra más razonable cuando resultara manifiestamente excesiva en proporción al perjuicio causado por el incumplimiento, atendidas las circunstancias del caso particular ${ }^{162}$.

La determinación convencional de los perjuicios anticipadamente por los contratantes, sea en el mismo contrato o en un acto posterior, siempre que se fije antes que se produzcan los daños, presenta la ventaja de que se evitan los costes y el tiempo que demore la acreditación de los perjuicios no fijados ${ }^{163}$. Si la determinación de la pena resultare manifiestamente excesiva ${ }^{164}$, el juez

\footnotetext{
157 Para ver el tipo de interés aplicable en diversos países de Europa. LANDO y BEALE (2003), pp. 668-670.

158 LANDO y BeAle (2003), p. 666. Al respecto, véase también: artículo 7:108 PECL. UNidROIT (2010), p. 26.

159 LANDO Y Beale (2003), pp. 666-667.

160 En el common law las penas son de dos clases: (i) penalti clauses y (ii) liquidated damages. Las primeras son ineficaces, pues se trata de cláusulas "in terrorem", con la finalidad de obligar al deudor a cumplir con su deber; en cambio, las segundas son cláusulas de estimación de daño, cuyo objetivo es determinar anticipadamente las posibles pérdidas que produzca el incumplimiento contractual, no pudiendo ser modificadas. Para determinar cuándo estamos frente a una u otra existe un criterio: si el monto de la indemnización es excesivo, se trata de una cláusula penal (caso Dumlop Pneumatic Tyre Co. Ltd. v. New Garage and Motor Co. Ltd. de 1915). Lando y Beale (2003), p. 675.

161 En este sentido, se impuso el civil law por sobre el common law. Zimmermann (2000), p. 132.

${ }^{162}$ En cuanto a la moneda en que se debe pagar la indemnización de daños y perjuicios, el artículo 9:510 dispone que "Los daños y perjuicios se calcularán en la moneda que refleje con mayor precisión las pérdidas sufridas por el lesionado", UNIDROIT (2010), p. 36.

163 Lando y Beale (2003), p. 671.

164 En los países del civil law se encuentra ampliamente reconocida esta facultad. Así, se pronuncian el "[...] ABGB austríaco § 1336 (2); Ley de contratos danesa, finlandesa y sueca, § 36; BW neerlandés,
} 
tiene la facultad para reducir la suma establecida, incluso cuando al momento de contratar la cantidad acordada aparecía como razonable ${ }^{165}$.

Por último, el art. 9:510 PECL dispone que "[L]os daños y perjuicios se calcularán en la moneda que refleje con mayor precisión las pérdidas sufridas por el lesionado"166.

\subsection{Reducción del precio}

En caso de existir un incumplimiento injustificado, procede la acción de reducción del precio, de origen romano ("actio quanti minoris"), consagrada en el artículo 9:401 de los PECL ["Derecho a reducir el precio"], que dispone: "(1) Quien es parte en el contrato y acepta una oferta de cumplimiento no conforme con el mismo puede reducir el precio. Esta reducción será proporcional a la diferencia entre lo que haya disminuido el valor de la prestación en el momento en que se produjo el ofrecimiento y el valor que hubiera tenido en ese momento un ofrecimiento conforme. (2) La parte que tiene derecho a reducir el precio conforme al apartado anterior y que ya hubiera pagado una suma superior a dicho precio, puede recuperar el exceso reclamándoselo a la otra parte. (3) La parte que reduce el precio no puede obtener al mismo tiempo una indemnización de daños y perjuicios por la disminución del valor de la prestación, pero sigue teniendo derecho a una indemnización por daños y perjuicios respecto de cualesquiera otras pérdidas que haya sufrido y que deban repararse conforme a la sección 5 de este capítulo" ${ }^{\prime 167}$.

Es común que los sistemas modernos contemplen esta clase de remedio, usualmente a propósito de la compraventa, el arrendamiento y el contrato de obra. Con todo, él no aparece en los Principios Unidroit ${ }^{168}$.

\section{Aspectos concretos para resolver entre los distintos remedios}

Lo que plantea el Derecho de remedios es que, frente al incumplimiento, desde una perspectiva objetiva, el acreedor puede optar entre los diferentes

art. 6:94; CC italiano art. 1348; CC francés y luxemburgués, art. 1152 (2); CC griego, art. 409, incluso si las partes hubieran pactado otra cosa; y BGB alemán \& 343. No obstante, en Alemania y Austria, las penas o pagos pactados en los contratos mercantiles no pueden reducirse, ver HGB $\S 348^{\prime \prime}$. LANDO y Beale (2003), p. 674.

165 LANDO Y Beale (2003), pp. 671-672.

${ }^{166}$ LANDO y BeAle E (2003), p. 675. En este sentido, se ha dicho que: "Ante la inmensa variedad de hechos que rodean el desarrollo de los negocios mercantiles, generalmente no es posible determinar con precisión la moneda más adecuada para compensar a la parte perjudicada". LANDO y BEALE (2003), pp. 676-677.

167 UNIDROIT (2010), pp. 30-31.

168 ZiMMERMANN (2000), p. 126. 
remedios. Los posibles conflictos entre remedios, o la sumatoria de ellos, naturalmente deben ser resueltos por el juez. El criterio fundamental para discriminar entre remedios es la buena fe. En torno a esta figura se produce una tensión natural entre los intereses del acreedor y los del deudor. El acreedor pretenderá que el remedio lo beneficie de la forma más extendida posible. Y el deudor pretenderá que el incumplimiento genere el menor impacto posible en su patrimonio. Otro aspecto relevante es si el juez puede recurrir a la expectativa rota del acreedor, como criterio objetivo, para dilucidar las preferencias entre remedios y/o establecer reglas de acumulación entre remedios. La dicotomía entre el interés de las partes es de difícil solución una vez que se genera el incumplimiento, aun desde la perspectiva de la expectativa rota del acreedor. Ello se debe a que el actor no sabrá hasta el final, en la etapa de ejecución, si realmente su pretensión procesal será satisfecha (independientemente de lo que decida el juez).

En la concepción literalista, la dicotomía estaba resuelta por cuanto el acreedor en principio sólo tenía derecho al cumplimiento forzado, como derecho principal, y, únicamente en caso de imposibilidad del cumplimiento "in natura", el acreedor podía recurrir a la resolución, más indemnización de perjuicios, como derecho supletorio. En cambio, conforme al Derecho de remedios, el acreedor cuenta con una libertad de elección de remedios, salvo casos de incompatibilidad.

La forma asignada por el Derecho de remedios para que operen los diferentes remedios es que, en principio, éstos sean acumulables entre sí, siendo la indemnización de perjuicios el derecho al que siempre podrá recurrir el acreedor, pero esa es sólo una regla general por cuanto ellos podrían ser incompatibles. De este modo, se ha señalado que los remedios son subsidiarios, aunque pueden ser acumulables en la medida en que no sean incompatibles entre sí y que la elección sucesiva de remedios no genere inconvenientes para el deudor. En este sentido, Vaquer entiende que el acreedor tiene una suerte de "ius variandi", que le permite intentar de forma subsecuente otro remedio tras haber probado fortuna con un primero (art. 8:102 PECL) ${ }^{169}$, pero siempre dentro de los límites de la buena fe en el ejercicio de los derechos (art. 1:201 PECL) ${ }^{170}$. El objeto de esta regulación es impedir que el acreedor, tras optar por la resolución contractual, solicite el cumplimiento en forma específica, ya que ello va a causar inconvenientes al

169 "Artículo 8:102: Acumulación de medios de tutela. Los medios que no sean incompatibles pueden acumularse. En particular, las partes no pierden su derecho a la indemnización por daños y perjuicios en caso de haber utilizado cualquier otra vía a la que tengan derecho".

170 "Artículo 1:201: Buena fe contractual. (1) Cada parte tiene la obligación de actuar conforme a las exigencias de la buena fe. (2) Las partes no pueden excluir este deber ni limitarlo". 
deudor ${ }^{171}$. En este mismo sentido, el art. III.-3:102 DCFR señala que los remedios, que no son incompatibles entre sí, son acumulables y reconoce expresamente la posibilidad de reclamar una indemnización al tiempo que se hace valer cualquiera de los otros remedios ${ }^{172}$. A su vez, tanto en los PECL como en los DCFR no existe problema en modificar la pretensión inicial si ella no es satisfecha en tiempo y forma (arts. 8:106 PECL ${ }^{173}$ y art. III.-3:102 DCFR) ${ }^{174}$.

Un criterio para determinar la incompatibilidad entre remedios es la buena fe (art. III.-1:103 DCFR). Una de las diferencias entre estas dos regulaciones es que la DCFR permite al deudor pagar la deuda, ya producido el incumplimiento, en la medida de lo razonable. De este modo, es posible concluir que el acreedor, frente al incumplimiento, puede recurrir a cualquier remedio y que, en torno a su acumulabilidad, se exige que ellos no sean incompatibles; además, en todo caso, siempre podría demandar la indemnización de perjuicios. Ahora bien, el presente trabajo se centrará en el criterio para determinar la incompatibilidad entre ellos y, con relación a este criterio, lo que se analizará serán las condiciones de procedencia como mecanismo objetivo para determinar la referida compatibilidad ${ }^{175}$.

Gómez señala, respecto de los DCFR, que "Una sección del capítulo relativo a los remedios frente al incumplimiento regular la subsanación por el deudor del cumplimiento no conforme [ "Cure by debtor of non-conforming performance»]; se trata de un derecho que se confiere al deudor dentro de ciertos límites de razonabilidad, en coherencia con el principio de la buena fe y con el fin

\footnotetext{
171 Díez-Picazo et al. (2003), p. 539.

172 Gómez (2012), pp. 43-44.

173 "Artículo 8:106. Comunicación concediendo un plazo adicional para el cumplimiento. (1) En todos los casos de incumplimiento, el perjudicado puede conceder a la otra parte una prórroga para proceder al cumplimiento, comunicándole dicha decisión. (2) En el transcurso de dicho plazo adicional, la parte perjudicada puede dejar en suspenso el cumplimiento de sus correlativas obligaciones y reclamar el pago de daños y perjuicios, pero no puede utilizar ningún otro medio de tutela. Ante una comunicación de la otra parte informándole de que no cumplirá en dicho plazo o si, vencido el plazo adicional, la obligación debida siguiera sin verse cumplida, el perjudicado podrá recurrir a cualquiera de los medios previstos en el capítulo 9. (3) Ante un retraso en el cumplimiento que no revista el carácter de esencial, si la parte perjudicada hubiera concedido a la otra parte una prórroga de duración razonable para proceder el pago, el perjudicado puede resolver el contrato al concluir el plazo previsto en la prórroga. Al comunicar la concesión de la prórroga, el perjudicado puede disponer que el contrato concluirá automáticamente si la otra parte no cumple en el plazo fijado. Si el plazo dispuesto es demasiado breve, la parte perjudicada sólo puede resolver el contrato o, en su caso, concluir éste de manera automática, cuando haya transcurrido un tiempo razonable desde el momento de la notificación".

174 Palazón (2014), p. 21.

175 La libertad de elección se permite también en el artículo 7.2.5 de los Principios Unidroit. El art. 7.2.5 de los Principios Unidroit expresamente permite el cambio de mecanismo.
} 
de mantener la relación contractual siempre que ello resulte posible". En igual sentido, el art. III.-3:202 DCFR permite dejar subsistente el contrato mediante el cumplimiento de una nueva prestación por el deudor ${ }^{176}$.

Como se aprecia de lo señalado precedentemente, la solución del Derecho de remedios, a este respecto, proviene de la aplicación de la buena fe y de la razonabilidad en torno a una reinterpretación de las obligaciones del contrato, como derecho del deudor, que permite discriminar en torno a remedios específicos. Otro tanto sucede respecto de las reglas de la imposibilidad en la ejecución. En el fondo, nos podemos preguntar lo siguiente: ¿sería posible discriminar entre los remedios conforme a la buena fe, que por ser una concepción objetiva puede ser complementada por criterios de razonabilidad en la discriminación que el juez debe hacer respecto de los remedios que procedan? Este tema ha sido abordado indirectamente por nuestra doctrina. Así, se sostiene una aplicación restrictiva a lo que comprende la CISG por "gestión razonable de los remedios contractuales $^{\prime 177}$. La referencia a la razonabilidad de la pretensión es específica en el Derecho de remedios en una serie de remedios. Así, por ejemplo, la declaración de resolución por incumplimiento del perjudicado debe hacerse en un plazo que sea razonable y opera de forma excepcional. La previsibilidad impone una cierta probabilidad de ejecución del daño por parte del deudor, cuestión que se exige para proceder a resolver el contrato. Lo que el Derecho exige es una conducta "razonable"178 a todos los sujetos que se encuentran en la misma situación. En síntesis, se "objetiviza" la conducta de los contratantes ${ }^{179}$.

López, respondiendo directamente la pregunta precedente, plantea al abuso del Derecho como un límite al derecho de remedios ${ }^{180}$. La concepción propuesta por López descansa sobre la categoría de contratos unilaterales y bilaterales, categoría que es estéril (desde que ambas nociones discurren sobre un beneficio interno o externo al contrato). Tampoco es posible recurrir al abuso del derecho como un mecanismo objetivo de discriminación entre diferentes remedios por

\footnotetext{
176 Gómez (2012), pp. 45-46.

177 López (2012), p. 15; Gandarillas (2009), pp. 440-446; Vidal (2008), p. 446.

178 VÁzQuez (1995), pp. 175-176.

179 Cabanillas (1998), p. 217.

180 López (2012), pp. 13-62. Con relación al derecho de los remedios del acreedor en Chile, véase: AlCalde (2015), pp. 579-600; AlCalde (2013), pp. 225-348; AlCAlde (2011), pp. 37-86; Barcia (2017), pp. 453-464; Barrientos (2014), pp. 57-82; Claro (1977), p. 193; Larraín (2003), pp. 83 y 84; Meza (1990), pp. 255 y 256; Ramos (2004), p. 239, y FueYo (1992), p. 339; Contardo (2015), pp. 1 y ss.; Contardo (2011), pp. 85-118; López (2012), pp. 26-30; Vidal (2006), pp. 468-469; Rivera (2017a), pp. 267-291; RIVERA (2017b), pp. 266-288. RIVERA (2017c), pp. 120-139; RIVERA (2017d), pp. 303-333; Rivera (2017e), pp. 40-53; RiverA (2016a), pp. 203-244; RiverA (2016b), pp. 223-233; RiverA (2016c), pp. 1-15; Vidal y De La MaZa (2014), pp. 15-38.
} 
cuanto el abuso del derecho se basa en un supuesto ajeno al ejercicio normal del derecho: su ejercicio abusivo. Nos parece que, para determinar el derecho a opción entre varios remedios, es mejor recurrir a una concepción moderna del contrato. $Y$ dentro de ella es especialmente valiosa la concepción de la expectativa rota del acreedor. En su determinación, lo esencial es recurrir a la distinción entre contratos onerosos y gratuitos, siendo para estos efectos relevante sólo la categoría de contratos onerosos conmutativos. A este respecto, el concepto de expectativa del acreedor se llenará de contenido conforme a la libertad contractual (concepción subjetiva) y al mercado, como concepción objetiva. El tema no es menor, por cuanto el contorno oneroso conmutativo es consustancial al mercado y a la justicia conmutativa; en cambio, la noción excluyente del Derecho de remedios es la de contrato gratuito. El contrato gratuito no por casualidad en los países del common law ni siquiera es un contrato, dicha figura obedece a la lógica de la justicia distributiva. Es en el contrato oneroso conmutativo en el que se generará un intercambio de expectativas entre las partes; en cambio, en el gratuito simplemente hay una intención de beneficiar exclusivamente a una parte. Por ello, es que los límites entre ambas formas contractuales -si es que a los actos gratuitos se les puede extender esta concepción- son sustancialmente diferentes. Desde una perspectiva del Derecho tradicional, los contratos gratuitos son formales, tienen una protección menor del ordenamiento jurídico (la acción pauliana es más exigente para el contrato oneroso), no se les aplican las cláusulas abusivas, se ven afectados por el error en la identidad del beneficiario y son revocables (como sucede con la revocación de la donación irrevocable por ingratitud del donatario, en la que, en principio, no opera el saneamiento, etc.). La determinación del derecho a opción entre varios remedios debe ser conforme a una noción de mercado y, por tanto, debe ser una noción que nos acerque al mercado perfecto. $Y$, dentro de la determinación ex post de la expectativa rota del acreedor, creemos que se puede recurrir a los conceptos de costos de transacción y al tratamiento de las externalidades. En tal sentido, se propone una noción de derecho de opción del acreedor que evite costos de transacción y que determine el contenido de la indemnización de perjuicios, como quiebre eficiente del contrato.

\section{A modo de conclusiones parciales}

El Código Europeo de Contratos se estructura, principalmente, sobre la base del principio de la autonomía de la voluntad ${ }^{181}$. Además, constituye, a diferencia de los PECL y del DCFR, un verdadero código, que le otorga una cierta ventaja,

181 HeSSELINK (2006), p. 157. 
pues el juez lo puede aplicar de manera precisa al caso concreto sometido a su conocimiento. El Proyecto de Pavía de Gandolfi pretende, en nuestra opinión, emular a los Restatements of the Law del Derecho norteamericano. Presenta las ventajas propias de un código civil: existe una cierta armonía entre sus normas, lo que atenúa la posibilidad de que existan contradicciones. Asimismo, consagra el incumplimiento objetivo (artículo 89), lo que está conforme con las modernas tendencias del Derecho civil. También resulta interesante la preferencia que el Proyecto le otorga al proceso de negociación, por sobre los remedios resolutorios.

Estimamos que el Código de Gandolfi exacerba el rol de la autonomía de la voluntad. Al parecer, se pretende revivir el proceso de dictación del Code francés ("laissez faire, laissez passer") ${ }^{182}$, que alzó a la autonomía de la voluntad al estatus de verdadero dogma, aun cuando, en nuestra opinión, nunca lo llegó a alcanzar ${ }^{183}$. El Proyecto de Gandolfi, al igual que el Code, se sustenta en la tesis voluntarista ${ }^{184}$ (fundamento del art. 1134 del Code) $^{185}$, que consagra la voluntad individual como el motor que hace eclosionar el negocio jurídico ${ }^{186}$. En este sentido, señalan los hermanos Mazeaud y Chabas que "[A] los ojos de los filósofos del siglo XVIII la voluntad es la fuente de todos los derechos"187-188.

Nos parece, a partir de lo señalado precedentemente, que más bien se están imponiendo unos criterios económicos que se alejan de los criterios tradicionales, pero que son de larga data en el Derecho europeo de los contratos ${ }^{189}$. Consideramos que el principio de la autonomía de la voluntad no es, por sí solo, capaz de explicar la relación contractual. El Derecho europeo ha recurrido a ciertas concepciones objetivas que permiten dar a los remedios una estructura más flexible que la del pacta sunt servanda ${ }^{190}$.

\footnotetext{
182 Larroumet (2003), pp. 94-95.

183 Alcubilla (2008), p. 47.

184 CARBONNIER (1956), p. 53.

185 MARTIN (1979), p. 188.

186 LaCruz et al. (2011), p. 329; Menezes (2005), pp. 396-397.

187 De Buen (1986), p. 210; Mazeaud et al. (1997), p. 146.

188 Esta tendencia tiene una larga data en España; así, por ejemplo, la STS de 20 de mayo de 1943 dispone que "No está en las facultades del juzgador negar la eficacia jurídica que a lo libremente pactado corresponde, cuando no hay motivo suficiente para declararlo contrario a las leyes, a la moral o al orden público".

SÁNCHEZ (2005), p. 46.

189 Walz (1943), p. 665.

190 Así, por ejemplo, respecto de la constitución del contrato se recurre a la existencia de una causa lícita que se sustente en el principio de la buena fe. Almagro (2000), p. 498.
} 
Un segundo problema que se atisba es que el Proyecto de Pavía choca con la tradición anglosajona del Derecho consuetudinario y jurisprudencial, lo que hace difícil pensar en una verdadera unificación del Derecho continental europeo con la tradición anglosajona.

Por otra parte, aun cuando no sea un texto legal vinculante, es indudable la influencia que han tenido los PECL, ya que han sido aplicados por tribunales nacionales, como si se tratase de leyes positivas. Con ello se cumple su pretendido afán de crear una superestructura en materia de contratos, sobre la base de los principios de autonomía de la voluntad y buena fe contractual. Los $P E C L$ se enmarcan dentro del proceso de unificación del Derecho europeo de las obligaciones, a diferencia de la CISG, que tiene carácter internacional. Lo anterior, sin embargo, no le restan mérito, toda vez que, al igual que la CISG, amalgaman elementos propios del common law con nociones del civil law, manifestando, creemos, una preferencia por el primero.

\section{El derecho a opción y AED: El contrato perfecto y los contratos de larga duración}

\section{La noción de contrato perfecto y la inclinación inicial hacia la indemnización de perjuicios y el cumplimiento forzado en el $A E D$}

Existe una nutrida literatura de $A E D$ a favor del quiebre eficiente del contrato en desmedro el cumplimiento forzado, que, sin embargo, se está comenzando a revertir ${ }^{191}$. De este modo, la tendencia en el $A E D$ a favor de la indemnización de perjuicios sobre el cumplimiento forzado debe matizarse. Al tener el acreedor la posibilidad de elegir entre el cumplimiento y la resolución con indemnización de perjuicios, se evita el proceso de que los tribunales determinen el quantum indemnizatorio de una forma eficiente ${ }^{192}$. Esta solución sería superior a optar por la indemnización como remedio preferente desde que el quiebre eficiente presupone que los tribunales son capaces de determinar el daño de forma eficiente. Así, contra la tendencia general del $A E D$ hace un tiempo atrás, ahora

\footnotetext{
191 Cooter y Ulen (1997), pp. 244-250; SChäfer et al. (2004), pp. 320-335; Friedman (2000) pp. 162-167. Así, Friedman señala que el cumplimiento en algunos casos será ineficiente, como si, por ejemplo, el beneficio social de la ejecución del contrato se esfuma a pesar de que el acreedor se verá beneficiado. $\mathrm{Y}$ a este respecto pone como ejemplo que una parte contrata para que una propiedad sea limpiada, pero por efecto de una caída en los precios, el valor de la propiedad es inferior al precio por limpiar el terreno. En este supuesto, evidentemente el mejor escenario es desechar el cumplimiento forzado por cuanto, a pesar que el contrato beneficia al acreedor, dicho beneficio es mayor que el beneficio social desde que el fin perseguido mediante el contrato por el deudor ya no será posible. Friedman (2000), p. 163.

$192 \mathrm{Y}$ ello es especialmente relevante desde que los tribunales tienden a subevaluar el monto de expectativa rota del acreedor en la indemnización de perjuicios. ULEN (1984), pp. 365-366.
} 
se señala que las partes -que tienen una información más adecuada sobre los costos de oportunidad y ejecución del contrato- podrían ex ante, si saben que el remedio predominante es el cumplimiento forzado, optar por una regulación eficiente del contrato. En otras palabras, el acreedor evaluará si demandar de cumplimiento o resolución con indemnización de perjuicios ${ }^{193}$. De este modo, en la actualidad el $A E D$ no difiere demasiado del derecho europeo de remedios, desde que concede al acreedor la opción por optar por el remedio más adecuado.

Sin perjuicio de lo anterior, Shavell especifica aún más la solución en torno al derecho de opción entre cumplimiento forzado e indemnización de perjuicios, señalando que la ejecución del contrato es desechada como regla general, por cuanto ella es deseable sólo en los casos de contratos perfectos. Para Shavell, los contratos que tienen como objeto la entrega de una cosa específica o la realización de un servicio concreto, son contratos perfectos y por ello deberían dar lugar a la ejecución del contrato. Así, en palabras de Shavell: "[t]he interpretation of specific performance depends on the nature of the contract obligation. Usually, specific performance refers to obligations to deliver a good or to perform a service, in which case it means that exactly that must be done"194.

El quiebre eficiente del contrato -excluye el derecho de opción del acreedor frente al incumplimiento, suponiendo que el acreedor puede optar entre el cumplimiento forzado y la resolución con indemnización de perjuicios, o la indemnización de forma autónoma- otorga al acreedor solamente un derecho a la indemnización de perjuicios que dependerá de dos factores:

a) La determinación de la Corte del perjuicio indemnizable -que cubre la expectativa rota del acreedor-, conforme a los siguientes dos criterios:

i) la previsibilidad del daño, $y$

ii) los costos de prevención marginales con relación al daño probable.

\footnotetext{
193 En este sentido, Schäffer y Ott señalan que el cumplimiento forzado puede generar los incentivos para que las partes tengan más cuidado con la determinación del contenido del contrato, pero también tiene el problema que hace que contratar sea más caro. Incluso, para los referidos autores, el cumplimiento forzado genera incentivos para negociar una vez incumplido el contrato entre acreedor y deudor, $y$, como el deudor valora más el uso alternativo que le ha dado al objeto del contrato -0 , en otras palabras, para el deudor el perjuicio del cumplimiento es muy alto-, habrá un amplio campo en el cual las partes podrán negociar para evitar el cumplimiento forzado. Pero ello supone que no existen costos de transacción o que ellos son bajos. Sin perjuicio de lo anterior, Schäffer y Ott reconocen que el cumplimiento forzado aumenta los costos de la contratación.

SCHÄFER y OtT (2004), pp. 329-332.

194 Aplicando la tesis de Shavell, en estos casos las solemnidades o formalidades en estas obligaciones (entrega de cosa o prestación de servicio) permitiría otorgar la calidad de indubitada a la obligación y facilitar su ejecución, evitando la creación de costos de transacción. En estos casos, para Shavell se impondría el cumplimiento forzado. SHAVELL (2004), p. 312.
} 
b) El alcance que se otorgue a la cláusula penal (función resarcitoria y/o punitiva).

En torno a la determinación del daño, por ejemplo, supongamos que un vendedor valora y vende un escritorio en USD 600 (el comprador lo valora en USD 800), pero concurre un segundo comprador, que le otorga un mayor valor y ofrece USD 1.000 por el escritorio. Conforme al quiebre eficiente del contrato, el Derecho debería permitir que el vendedor resuelva el primer contrato, indemnizando al primer comprador en su expectativa rota-que es una cifra que va entre lo que está dispuesto a pagar, es decir, los USD 600, y lo que realmente valora la cosa- y asignar la cosa al segundo comprador. Fíjense que ésta es una situación de Máximo de Pareto, corregida por KaldorHicks, por cuanto se genera el máximo de bienestar social posible: los dos compradores y el vendedor están mejor que si se hubiese obligado al vendedor a cumplir con el contrato. Ahora bien, está claro que si el vendedor sabe que la Corte lo condenaría ex ante a pagar USD 1.000 por incumplimiento del primer contrato de venta, por concepto de valoración de la cosa y daño moral, se impondrá el cumplimiento ineficiente del contrato en la medida en que haya de haber costos de transacción ${ }^{195}$. Para permitir el quiebre eficiente del contrato, la Corte debería calcular la indemnización de perjuicios conforme a la expectativa rota del acreedor, que no equivale al contenido del contrato, por cuanto el acreedor no tiene que cumplir con la obligación correlativa respecto de la cual es deudor. Tradicionalmente, la solución para la mayoría de la literatura del $A E D$ estará en la determinación del daño. Y a este respecto los daños se clasifican en restitution, reliance y expectation ${ }^{196}$. Los daños de expectativa -que equivalen a nuestro lucro cesante-, los daños

\footnotetext{
195 Para Shavell, los casos de valoración excesiva de la indemnización de perjuicios generan un incentivo al cumplimiento. SHAVELL (2004), p. 305.

Naturalmente, se estima que este incentivo es ineficiente desde que pueden haber costos de transacción que impidan la negociación entre el primer comprador -que tendría la cosa producto del incentivo regulatorio a favor al cumplimiento del contrato- y el segundo comprador, que la valora más, aun si la cláusula penal corresponde a la real expectativa rota del acreedor. COOTER y ULEN (1997), pp. 244-250.

196 Los daños más amplios son los basados en "injured party's expectation" y ellos son conceptualizados por Farnsworth como "[D] amages based on expectation should therefore take account of any circumstances peculiar to the situation of the injured party, including that party's own needs and opportunities, personal values, and even idiosyncrasies. As we shall see shortly however, there are important limitations on damages that often hold the injured party to a more objective valuation of its expectation. In addition, the basic principle is subject to the important qualification that the injured party cannot recover costs of litigation (...). The purchaser was not, "entitled to any damages for the fancied goodness of the bargain, which he supposes he has lost»". Por tanto, el daño debe acreditarse; no basta que éste sea razonable. Sin perjuicio de lo cual, la referida compensación debe dejar al acreedor en el mismo estado en que hubiese encontrado de ejecutarse el contrato. A este respecto, Fischer señala que "[T] he compensatory aspect of the expectancy interest lies primarily in its dysfunctionality. A compensatory award equals what the plaintiff would have received had
} 
de confianza -que equivalen a nuestro daño emergente- y los costos de oportunidad determinan el sustituto perfecto de la expectativa rota del acreedor, pero su cálculo no está exento de problemas ${ }^{197}$.

Volviendo al ejemplo precedente, la cláusula penal podría ser un buen sucedáneo del cumplimiento forzado, como derecho alternativo del acreedor, que juega como una evaluación anticipada del daño, como podría ser si el incumplimiento se valora en USD 150 (por ejemplo, conforme al aumento del precio que alternativamente el primer comprador puede obtener o tuvo que pagar en el mercado), pero si la cláusula penal es punitiva, como si se valora en USD 350, se impediría el incumplimiento eficiente del contrato ${ }^{198}$. Sin perjuicio de lo anterior, la cláusula penal puede ser un adecuado instrumento para generar los incentivos cumplimiento eficiente o incumplimiento eficiente. Pero la regulación de estas figuras, tanto en la ley como en su

the bargain not been disrupted. The award and the loss being equal, the plaintiff is placed in the position she would have been had the bargain been performed". FARNSWORTH (1999), pp. 784-785, y FISCHER (2006), p. 28.

${ }_{197}$ A este respecto, Ulen estima que el cumplimiento forzado es un remedio más adecuado que la indemnización de perjuicios bajo parámetros de eficiencia. Y sustenta su posición en los siguientes argumentos: (a) el cumplimiento forzado genera los incentivos para regular adecuadamente los riesgos en el contrato por las propias partes; (b) protege la valoración subjetiva del contenido del contrato por las propias partes; (c) los costes asociados al incumplimiento son menores a cualquier otro remedio, y (d) la determinación de la indemnización de perjuicios -la expectativa rota del acreedor- por los tribunales suele infravalorar los perjuicios.

De este modo, Ulen señala que "[F] irst, if contractual parties are on notice that valid promises will be specifically enforced, they will more efficiently exchange reciprocal promises at formation time. In particular, they will have a stronger incentive than currently exists under the dominant legal remedy to allocate efficiently the risks of loss from breach rather than leaving that task, in whole or in part, to the court or to post-breach negotiations conducted under the threat of a potentially inefficient legal remedy. Second, and perhaps most importantly, specific performance offers the most efficient mechanism for protecting subjective values attached to performance. Thus, it promotes contract breach only if it is efficient, that is, if someone will be better off and no one will be worse off because of the breach. In this regard, specific performance and an expansive enforcement of stipulated remedies constitute integral and inseparable parts of a unified theory of efficient contract remedies. Third, if specific performance were the routine remedy, the post-breach costs of adjusting a contract in order to move the promise to the highest-valuing user would be lower than under the most efficient legal remedy. The central reason for this is that under specific performance the costs of determining various parties' valuation of performance are borne by those parties in voluntary negotiations. This means that the costs of determining willingnessto-pay are borne by those most efficiently placed to determine that amount. Finally, because the costs of ascertaining any subjective values of the innocent party through evidence presented to a court are so high and because, therefore, the possibility of undercompensating the innocent party through a damage remedy is high, specific performance is far less likely to be undercompensatory and far more likely to protect the breachee's subjective valuation than is any other judicially imposed contract remedy". ULEN (1984), pp. 364-365.

${ }^{198}$ En este sentido, Shavell señala que "[N] ote too that if a monetary penalty can be employed to induce performance, then specific performance is equivalent to a damage measure with a high level of damages". Shavell (2004), p. 312. 
aplicación por los tribunales, puede generar importantes costos de transacción. Y ello dependerá de la concepción que los jueces tengan del contrato. El contrato para el $A E D$ es un simple intercambio de expectativas, dadas determinadas condiciones de intercambio, que, en caso de conflicto, el juez debe replicar conforme a lo que se ha denominado "contrato perfecto". Y, en este sentido, una sobrevaloración de los daños, una inadecuada interpretación de la cláusula penal, transforma la cláusula penal en un costo de transacción. El contrato perfecto es un acuerdo en torno a costos y valores de mercado del bien o servicio de que se trata, en el cual no existirían fallas de mercado; es decir, con información perfecta, sin costos de transacción, ni externalidades negativas. Dicho análisis determinará la distribución de riesgos, confianza e información entre las partes, lo que asignará en definitiva el daño. Por ello, en los países del common law sólo se acepta la evaluación anticipada de los perjuicios, pero se desecha el otorgarle una función punitiva a la pena ${ }^{199}$, aunque en casos excepcionales se acepta dicha función, como en los contratos de confianza.

\section{Los contratos indefinidos y los incentivos a su renegociación en torno a los cambios de circunstancias}

Uno de los aspectos en que coinciden el Derecho moderno de los contratos y el $A E D$ es precisamente en la promoción e implementación de incentivos

\footnotetext{
199 Para el common law las penalties clauses son nulas. De este modo, Wicker señala que " $[\mathrm{H}]$ owever, exceptionally, when for example the amount fixed is extravagant so that it seems almost impossible that the parties have attempted in good faith to estimate the amount of the loss, this clause will be requalified as penalty clause and will not be enforced by the judge, who will estimate and award as compensation the actual value of the loss suffered". WICKER (2008), p. 314. En igual sentido, Zimmerman señala que "[...] las cláusulas penales no han sido jamás rechazadas en la tradición jurídica continental. Cumplían importantes funciones sirviendo en particular para presionar a quien no quería o no podía realizar la prestación debida (nota al pie). En la Inglaterra medieval jugaron un papel por lo menos igual de importante las llamadas penal bonds que desempeñaban cometidos similares (...). También tanto en derecho romano como en derecho inglés se percibió el peligro que suponían las cláusulas penales. De ahí que los juristas romanos desarrollaban una serie de mecanismos para limitarlas (...), que el tiempo demostró que no bastaban. Por eso, bajo el influjo de los canonistas medievales, se modeló un nuevo medio de control: los tribunales estaban facultados para reducir las cláusulas desmesuradas ad bonum et aequum (...). Esta facultad (excepcional) de moderación puede hallarse en diversos Códigos modernos, entre ellos el BGB (...). Los tribunales de common law adoptaron una estrategia más radical: declarar la completa inadmisibilidad de las cláusulas penales, pero sólo de aquellas que servían para presionar al deudor, sin afectar a las cláusulas liquidatorias de daños y perjuicios (...). Esta distinción (que curiosamente ha encontrado acogida en el derecho alemán (...) comportó importantes dificultades para delimitar ambas figuras (...), y no ha prosperado, lo que se ha traducido en una pérdida no sólo de seguridad sino también de justicia para algunos casos concretos. No es sorprendente, por consiguiente, que el proyecto del profesor McGregor de un Código de derecho contractual haya equiparado las cláusulas liquidatorias y las cláusulas penales en sentido estricto (...), y que, comprensiblemente, los Principios de Derecho Contractual Europeo hayan seguido el modelo continental (...)". ZIMMERMANN (2000), pp. 45 y 46.
} 
regulatorios en torno a la negociación de contratos de larga duración, en especial en los contratos de suministro. Esta posibilidad es reconocida limitadamente por el $A E D$. La renegociación es vista por el $A E D$ como un nuevo contrato. Las partes, en el mundo real, a pesar que renegociar vaya en su beneficio, no siempre lo harán. Así, Shavell señala que a pesar que la renegociación sea deseable por ambas partes, ella no se producirá en muchos casos. En un primer grupo de casos la demora en la toma de decisiones puede generar un costo mayor para una de las partes. En este supuesto, esta parte preferirá no renegociar, y romper el contrato o demandar de cumplimiento, según el caso. En un segundo grupo las asimetrías de información harán imposible la renegociación. Finalmente, puede ser que los beneficios del contrato deban ser negociados y ello impida la renegociación ${ }^{200}$.

El $A E D$ sugiere que la renegociación del contrato desplazará la necesidad de celebrar un contrato perfecto. En cierto modo, para Shavell, el contrato perfecto sería el sustituto al derecho de remedios ${ }^{201}$. Los incentivos regulatorios para llevar a cabo la renegociación sólo funcionarán cuando los costos de transacción sean cercamos a cero. En los PECL, más que establecerse procesos de renegociación en contratos de tracto sucesivo, lo que se hace establecer una serie de mecanismos para mantener el contrato, como el otorgamiento de un plazo razonable previo a la resolución del contrato. En cierta forma se trata de una versión remozada del pacta sunct servanda. Los referidos instrumentos no tratan de reconducir los casos de incumplimiento de estos contratos a un proceso de negociación, aunque otorgan algunas herramientas que conducen a ello, como la propia cláusula penal.

El Anteproyecto de Código Civil europeo en el art. 111, precedentemente analizado, se inclina a favor del cumplimiento específico al otorgar una mayor posibilidad de ejecución de dicho derecho que los PECL. Por ello, es difícil determinar si la estructura del derecho de remedios, respecto de los remedios concretos, es o no eficiente, lo que dependerá finalmente de la determinación que la Corte haga de los perjuicios. Y, a este respecto, como se vio el desarrollo de los perjuicios en los PECL no se aleja del Derecho moderno de los contratos.

\section{La cláusula penal como sucedáneo del cumplimiento forzado.}

Los PECL vinculan la rebaja de la pena, que es calificada como manifiestamente excesiva, a los siguientes dos criterios:

a) En proporción al daño provocado por el incumplimiento, y

200 Shavell (2004), p. 314.

201 Shavell (2004), pp. 316-317. 
b) Considerando las demás circunstancias. En las demás circunstancias se podría analizar la rebaja de la pena, conforme a la información del contrato y los costes de transacción.

El quiebre eficiente del contrato también se puede tomar como un criterio general para permitir la rebaja de la pena, por cuanto se desecha su eventual función punitiva, desde que ella queda vinculada al daño. Así, la regla general, en ambos sistemas (el derecho de remedios y el $A E D$ ), es que se desecha la sobrevaloración de los perjuicios. Por tanto, un criterio de rebaja de la pena podría ser el quiebre eficiente del contrato. Pero esa es sólo una regla general.

Veamos algunas situaciones en las cuales el $A E D$ acepta la función punitiva en la cláusula penal. En primer lugar, la cláusula penal puede ser una garantía de cumplimiento en los contratos que eventualmente generen un alto riesgo de daño para el acreedor o en contratos en que la Corte presumiblemente subvalorará los daños. Así, Kornhauser sostiene que, en algunos supuestos, la cláusula penal es eficiente, como si una parte, para entrar a un mercado, debe celebrar una cláusula penal que asegure un alto estándar de calidad del producto o servicio. En realidad, lo que sucede es que la cláusula penal será eficiente en los casos en que por algún motivo la indemnización de perjuicios no cubre todos los daños que genera el incumplimiento. Para Kornhauser, ello se produce en el caso en que las expectativas de riesgo de las partes sean sustancialmente diferentes. En dicho supuesto, la racionalidad de la cláusula penal puede llevar a establecer una pena que mida estas diferencias de apreciación y dicha medida es mejor que recurrir a la solución judicial (ello se presenta desde una perspectiva interna al contrato). Sin perjuicio de lo cual la cláusula penal se podría justificar también desde una perspectiva externa al contrato. De este modo, podría ser que los tribunales no evalúen adecuadamente la pérdida reputacional, que significa para el acreedor el estar asociado a productos de un estándar inferior al convenido. Por otra parte, el deudor acordará una cláusula penal en la medida en que el aumento del riesgo, al asumir la pena, le sea efectivamente compensado, como podría ser a través de un aumento de precio o que le conceda acceso a un mercado o negocio al cual sólo a través del contrato con cláusula penal tendría acceso.

En resumidas cuentas, la cláusula penal punitiva impedirá el quiebre eficiente sólo en los casos en que el acreedor esté dispuesto a pagar un sobreprecio porque el deudor acepte una cláusula penal punitiva. Y, como suponemos que el acreedor es racional, sólo lo hará en los casos precedentemente analizados.

Un segundo aspecto, que resalta Kornhauser, es que la cláusula penal punitiva puede adelantar información relevante entre las partes o incentivar que 
se releve dicha información ${ }^{202}$. Así ocurrirá por ejemplo si una empresa, que se ha adjudicado una licitación, a su vez, tiene que licitar parte de la obra adjudicada y se presentan dos empresas a su licitación. La primera es una empresa de reconocido prestigio en el rubro, pero que cobra un precio sumamente alto, y la segunda una empresa nueva, que cobra un precio sustancialmente más bajo. En este supuesto, la compañía, que se adjudica la licitación, debe evaluar el riesgo de incumplimiento de la segunda empresa; por cuanto ella, a su vez, debe cumplir con los tiempos que le imponen las bases de licitación y las consecuentes multas por atraso. Ciertamente, esto es relevante para la compañía que se ha adjudicado la licitación, tanto desde los costos reputacionales (primer supuesto analizado) como respecto de las altas multas que debería pagar por atraso de las obras. Una cláusula penal que fuese punitiva anticipa información sobre el cumplimiento de la segunda empresa licitante. El establecer una pena alta, prácticamente punitiva, otorgará una información relevante respecto de la segunda empresa, o más bien una garantía de que ella cumplirá con los tiempos de la obra.

Asimismo, si el sistema de indemnización de determinación de los perjuicios no funciona -como si el sistema judicial es poco eficiente ${ }^{203}$-, la cláusula penal podría ser un buen remedio para evitar decisiones ineficientes de la corte ${ }^{204}$.

Sin perjuicio de lo anterior, una cláusula penal alta aumenta los costos de negociación del contrato, por cuanto ambas partes tendrán cuidado en la determinación del contenido del contrato, dados los efectos onerosos que la cláusula penal genera en el patrimonio del deudor o de ambas partes (ello dependerá del alcance de la cláusula penal) ${ }^{205}$. Por ello, el deudor se asegurará con cumplir con un estándar mayor al razonable y que el contrato no cuente con eventuales vacíos regulatorios. Y ello es caro. Además, la cláusula penal

202 Kornhauser (1986), pp. 720-721. En igual sentido se puede consultar a Ulen. Para el referido autor, la cláusula penal punitiva puede cumplir dos funciones: la primera es como seguro contractual de cumplimiento y la segunda es como incentivo para compartir información confiable respecto de las reales capacidades de cumplimiento. ULEN (1984), pp. 351-352.

${ }^{203}$ En este sentido, Posner señala que "[E]xpectation damages are also undesirable if courts have trouble determining the parties' valuations at the time of breach. The better remedy is specific performance, because the latter does not require the court to determine the promisee's valuation", POSNER (2002), p. 7.

${ }^{204}$ Cooter y Ulen justifican la función punitiva de la cláusula penal en las siguientes dos situaciones: (a) como un seguro de cumplimiento para el acreedor y (b) como una forma de incentivar el compartir la información que las partes tienen previo al contrato.

COOTER Y ULEN (2008), pp. 366-367.

205 Shavell señala que en realidad el cumplimiento forzado es más eficiente respecto de los contratos en que el deudor se obligó a transferir la propiedad de una especie o cuerpo cierto y que, a su vez, la indemnización de perjuicios es más eficiente en compraventa de mercaderías estandarizadas. Conforme a ello, la cláusula penal punitiva sería eficiente en el primer escenario. SHAVELL (2006), p. 835. 
puede subir los costos de renegociación del contrato, por cuanto la parte beneficiada con la cláusula penal podría aprovecharse de los vacíos contractuales ${ }^{206}$. En este sentido, la cláusula penal genera un doble efecto. Por una parte, evita que un contratante no declare toda la información relevante al momento de contratar -reduce las asimetrías de información-, pero por la otra hace que el deudor tenga más cuidado en la determinación del contenido del contrato, lo que hace que el costo de contratar aumente.

Finalmente, la cláusula penal punitiva sería deseable si es que se prefiere el cumplimiento forzado, como un remedio prevalente, y esta es la posición de algunos autores en $A E D$, como ya se analizó. Sin embargo, esta posibilidad estaría vetada en los PECL.

\section{La posibilidad de renegociar el contrato, una vez producido el incumplimiento, genera un análisis diferente de los remedios entre sí}

Como ha destacado Ulen, en la medida en que los costos de negociación sean bajos, altera la preferencia por la indemnización de perjuicios sobre los demás remedios. En este sentido, una falta de criterios jurisprudenciales, que fijen con exactitud cómo opera el derecho opción, puede ser un importante costo de transacción ${ }^{207}$. Así, la buena fe o la razonabilidad-como criterios objetivos de determinación del derecho opción- deben ser claros; de lo contrario, sólo se aumentarán los costos de transacción.

\section{Conclusiones finales}

a) El sistema de remedios reduce los costos de transacción, eliminando el problema de la imputabilidad en la resolución, pero mantendría el incumplimiento esencial como supuesto de la pretensión resolutoria. El otorgamiento de un plazo dentro del cual el deudor debe cumplir el contrato tiene tratamientos

\footnotetext{
206 De esta forma, Posner señala que "[...] it discourages parties from opportunistically concealing information from each other. If one party knows about the ambiguity of the word "chicken", and prefers the majoritarian meaning, and the other party does not know about the ambiguity, then the first party would have no incentive to disclose the ambiguity to the second, unless a penalty default rule held the informed party to the less favorable meaning". POSNER (2002), p. 10.

207 En este sentido, Ulen señala que "[T] hese models ignore (se refiere al modelo que concluye que la medición de los daños como expectativa rota del acreedor es superior Pareto con relación a los otros remedies, desarrollado por Shavell), whether, the possibility of recontracting or renegotiating after formation and after the seller's announcement of his intention to breach. Sin perjuicio de lo cual, más adelante Ulen señala que los trabajos de Rogerson llevan a preferir el cumplimiento forzado sobre otros remedios, conforme a un criterio parto-superior. Sin embargo, para la mayoría de la literatura sobre AED se inclina a favor de la indemnización de perjuicios, basado en la expectativa rota del acreedor, como el remedio que conduce al incumplimiento eficiente del contrato. Ulen (1984), p. 363.
} 
diversos. En los $P E C L$, la concesión no es graciosa por parte del acreedor ${ }^{208}$ y, en caso de que sea razonable y el deudor no cumpla, otorga derecho de resolución, aunque el incumplimiento no sea esencial (arts. 8:106 (3) y 9.301 (2) PECL) ${ }^{209}$.

b) Lo realmente interesante del derecho de remedios es que la indemnización de perjuicios es un remedio que, siendo autónomo, puede complementar a los otros. Ello podría ayudar a evitar al problema de la subvaloración del daño y los desincentivos en torno al cumplimiento eficiente.

c) La falta de exigencia de culpa en la resolución se justifica en que su función es eminentemente distributiva, desde el patrimonio del deudor al patrimonio del acreedor. Ello se debe fundamentalmente a que la resolución en ningún caso afecta el quiebre eficiente del contrato, como se aprecia del supuesto en que el vendedor transfiere la cosa a un segundo comprador y el primer comprador, que ha pagado el precio, solicita la resolución del contrato, es decir, la restitución del precio.

Finalmente, el número de remedios de que efectivamente goza el acreedor, frente al incumplimiento, no depende de un juicio subjetivo de imputabilidad respecto del deudor. Sin embargo, de ser el incumplimiento excusable, la parte perjudicada no está legitimada para exigir el cumplimiento ni para reclamar una indemnización por daños y perjuicios, como se desprende del art. 8:101 PECL ${ }^{210}$.

${ }^{208}$ Este plazo es planteado como una concesión graciosa del acreedor en el art. 8:106 (2) y (3), pero es obligatorio en cuanto el derecho para ejercer la pretensión de resolución conforme al art. 9:303 (1). De este modo, la referida norma establece lo siguiente: "Artículo 9:303. Comunicación de la resolución: (1) El ejercicio del derecho de resolución del contrato requiere una comunicación al respecto a la otra parte".

209 "Artículo 8:106: Comunicación concediendo un plazo adicional para el cumplimiento. (1) En todos los casos de incumplimiento, el perjudicado puede conceder a la otra parte una prórroga para proceder al cumplimiento, comunicándole dicha decisión. (2) En el transcurso de dicho plazo adicional, la parte perjudicada puede dejar en suspenso el cumplimiento de sus correlativas obligaciones y reclamar el pago de daños y perjuicios, pero no puede utilizar ningún otro medio de tutela. Ante una comunicación de la otra parte informándole de que no cumplirá en dicho plazo o si, vencido el plazo adicional, la obligación debida siguiera sin verse cumplida, el perjudicado podrá recurrir a cualquiera de los medios previstos en el capítulo 9. (3) Ante un retraso en el cumplimiento que no revista el carácter de esencial, si la parte perjudicada hubiera concedido a la otra parte una prórroga de duración razonable para proceder el pago, el perjudicado puede resolver el contrato al concluir el plazo previsto en la prórroga. Al comunicar la concesión de la prórroga, el perjudicado puede disponer que el contrato concluirá automáticamente si la otra parte no cumple en el plazo fijado. Si el plazo dispuesto es demasiado breve, la parte perjudicada sólo puede resolver el contrato o, en su caso, concluir éste de manera automática, cuando haya transcurrido un tiempo razonable desde el momento de la notificación".

210 VAQUER (2003), p. 539.

En igual sentido se puede consultar a Díez-Picazo, Roca I Trias y Morales Moreno (2003), p. 539. Y, como indica Vaquer, el criterio de la subsidiariedad se aplica conforme a la razonabilidad y la buena fe (art. 7.2.5 Unidroit). 


\section{BiBLIOGRAFíA CitADA}

Academia de Pavia (2009): Código Europeo de Contratos (Madrid, Editorial Reus).

Adame Goddard, Jorge (2009): "Capítulo 1. Bases doctrinales para un derecho contractual internacional", en: Bosch, Esteve (director), Derecho contractual europeo. Problemática, propuestas y perspectivas (Barcelona, Bosch), pp. 33-50.

AlCalde Silva, Jaime (2015): "Bases para una sistematización de los efectos de la resolución por incumplimiento", en: Vidal, Álvaro; Severin, Gonzalo, y Mejías, Claudia (editores), Estudios de Derecho Civil X (Santiago de Chile, Thomson Reuters - LegalPublishing), pp. 579-600.

(2013): "Algunas consideraciones sobre los presupuestos de la resolución contractual", en: AA.VV., Estudios de Derecho Civil en homenaje a don Lorenzo de la Maza Rivadeneira (Santiago de Chile, Facultad de Derecho, Universidad Gabriela Mistral), pp. 225-348.

(2011): "El tratamiento de los incumplimientos recíprocos en el derecho chileno", en: Carvajal, Patricio, y Miglietta, Massimo (editores), Estudios jurídicos en homenaje al profesor Alejandro Guzmán Brito (España, Edizioni dell'Orso), pp. 37-86.

Alcubilla, Enrique (2008): Enciclopedia Jurídica La Ley (Wolters Kluwer España Madrid, La Ley), Vol. 5.

Andreu Martínez, Belén (2003): "«Incumplimiento anticipado»: regulación en los Principios de Derecho Contractual Europeo y soluciones a la vista del Código Civil español", en: Espiau, Santiago, y Vaquer, Antoni (coordinadores), Bases de un Derecho contractual europeo (Valencia, Tirant lo Blanch), pp. 333-340.

Arroyo I Amayuelas, Esther (2003): "Textos básicos de Derecho privado europeo. Acquis communautaire y Derecho civil futuro", en: Espiau, Santiago, y Vaquer, Antoni (coordinadores), Bases de un Derecho contractual europeo (Valencia, Tirant lo Blanch), pp. 209-238.

Arroyo I Amayuelas, Esther (2002): "Estudio preliminar: Las perspectivas de un Derecho Privado Europeo", en: Schulze, Reiner, y Zimmermann, Reinhard (recopiladores), Textos básicos de Derecho Privado Europeo. Recopilación (Madrid, Marcial Pons), pp. 639-663.

Association Henri Capitant des Amis de la Culture Juridique Française (2008): Principes contractuels communs (París, Société de législation comparée), Vol. 7. 
Barcia LehmanN, Rodrigo (2017): “Una revisión del «ius electionis» en el denominado derecho de remedios", en: Corral, Hernán, y Manterola, Pablo (editores), Estudios de Derecho Civil XII (Santiago de Chile, Thomson Reuters), pp. 453-464.

BarRientos Camus, Francisca Ma (2014): "La articulación de remedios en el sistema de la responsabilidad civil del consumo", en: Revista de Derecho Pontificia Universidad Católica de Valparaíso ( $\left.N^{\circ} 42\right)$, pp. 57-82.

BAsSEnGE, Peter et al. (2002): Palandt Bürgerliches Gesetzbuch (München, Verlag C. H. Beck).

Cabanillas Sánchez, Antonio (1998): "Parte III.- Compraventa de mercaderías, arts. 25 a 29", en: Díez-Picazo, Luis, y Ponce de León, Luis (directores), La compraventa internacional de mercaderías. Comentario de la Convención de Viena (Madrid, Civitas), pp. 209-239.

CARbOnNier, Jean (1956): Droit civil (París, Presses Universitaires de France), Vol. 4. Carrasco Perera, Ángel (2003): "Failure, breach and non-conformity in contracts. A Spanish and European approach", en: Espiau, Santiago, y Vaquer, Antoni (coordinadores), Bases de un Derecho contractual europeo (Valencia, Tirant lo Blanch), pp. 297-320.

Claro Solar, Luis (1977): Explicaciones de Derecho Civil chileno y comparado (Santiago de Chile, Editorial Jurídica de Chile), Vols. VI, XI-II.

Tisserand-Martin, Alice et al. (2012): Code Civil, 112 édition, Edition 2012 (París, Éditions Dalloz).

Cnudmi (2011): "Convención de las Naciones Unidas sobre los Contratos de Compraventa.

Internacional de Mercaderías". Disponible en: https://uncitral.un.org/sites/uncitral.un.org/files/media-documents/uncitral/es/v1057000-cisg-s.pdf [visitado el 15.02.2015].

Comisión de Derecho Europeo de los Contratos (2000): Principios de Derecho Europeo de los contratos. Disponible en: http://campus.usal.es/ derinfo/ Material/LegOblContr/PECL\%20I+II.pdf [visitado el 15.02.2015].

ContaRdo GonzÁlez, Juan (2015): Indemnización y resolución por incumplimiento (Santiago de Chile, Thomson Reuters).

(2011): "Los criterios de interés contractual positivo y negativo en la indemnización de perjuicios derivada de resolución contractual", en: Revista de Derecho de la Universidad Católica del Norte (Vol. 18, № 1), pp. 85-118.

CoOter, Robert, y Ulen, Thomas (1997): Derecho y economía (versión en castellano) (México, Fondo de Cultura Económica). 
De Buen Lozano, Néstor (1986): La decadencia del contrato. Con un Apéndice «veinte años después» (México, Porrúa).

De CAstro Vítores, Germán (2003): "La cláusula penal. Utilización y acumulación de los remedios. Tutela preventiva y sumaria. Referencia al arbitraje", en: Vattier, Carlos; De La Cuesta, José, y Caballero, José (directores), Código Europeo de Contratos. Academia de lusprivatistas Europeos (Pavía) (Madrid, Dykinson), Vol. II, pp. 619-648.

De Priego Fernández, Verónica (2012): “Derecho contractual europeo y evicción: la superación del régimen de saneamiento", en: Gómez, María (coordinadora), Cuestiones sobre la compraventa en el Código Civil. Principios europeos y Draft (Madrid, Dykinson), Vol. II, pp. 195-234.

Díez-Picazo, Luis; Roca I Trías, Encarna, y Morales Moreno, Antoni (2003): Los principios del derecho europeo de contratos (Madrid, Civitas).

FARNSWORTH, Edward (1999): Contracts (Aspen, Editorial Advisory Board, Aspen Law \& Business, Aspen Publishers, Inc.).

FISCHER, James (2006): Understanding remedies (San Francisco, Lexis Nexis).

Friedman, David (2000): Law's order. What economics has to do with law and why it matters (New Jersey, Princeton University Press y Princeton).

FueYo LANERI, Fernando (1992): Cumplimiento e incumplimiento de las obligaciones (Santiago de Chile, Editorial Jurídica de Chile).

Gandarillas Serani, Cristián (2009): "Algunas consideraciones acerca del deber de mitigación o minimización del daño frente al incumplimiento contractual", en: Pizarro, Carlos (coordinador), Estudios de Derecho Civil IV (Santiago de Chile, LegalPublishing), pp. 440-446.

García Cantero, Gabriel (2010): Estudios sobre el Proyecto de Código Europeo de Contratos de la Academia de Pavía (Madrid, Reus).

(2009): “¿Civil law «versus» common law..., o viceversa?", en: Revista Jurídica del Notariado ( $\mathrm{N}^{\circ} 69$ ), pp. 411-440.

García Cantero, Gabriel (s/f): "La traducción española de la parte general del Código Europeo de Contratos". Disponible en: http://www.unizar.es/ [visitado el 15.02.2015].

GARRO, Alejandro, y ZuPPI, Alberto (1990): Compraventa internacional de mercaderías (Buenos Aires, Ediciones La Rocca).

Gómez CAlle, Esther (2012): "Los remedios ante el incumplimiento del contrato: Análisis de la Propuesta de Modernización del Código Civil en materia de obligaciones y contratos y comparación con el Borrador del Marco Común de Referencia", en: Anuario de Derecho Civil (Vol. LXV, No I), pp. 29-102. 
Hesselink, Martijn (2006): "The Politics of a European Civil Code", en: Hesselink, Martijn (editor), The Politics of a European Civil Code (The Haghe, Kluwer Law International), pp. 143-170.

Lacruz Berdejo, José Luis et al. (2011): Elementos de Derecho Civil II. Derecho de obligaciones, Quinta Edición (Madrid, Dykinson), Vol. I.

Lando, Ole, y Beale, Hugh (2003): Los Principios de Derecho Contractual Europeo Partes I y II (Traducc. Pilar Barres Benlloch, José Miguel Embid Irujo y Fernando Martínez Sanz, Madrid, Colegios Notariales de España).

LarRaín Ríos, Hernán (2003): Teoría general de las obligaciones (Santiago de Chile, LexisNexis).

Larroumet, Christian (2003): Droit civil. Les obligations. Le contrat, 5e édition (París, Económica), Vol. 3.

López Díaz, Patricia (2012): "El abuso del derecho de opción del acreedor y su importancia en la construcción de un sistema equilibrado de remedios por incumplimiento contractual", en: Revista Chilena de Derecho Privado Diciembre (No 19), pp. 13-62.

Kornhauser, Lewis (1986): "An Introduction to the Economic Analysis of Contract Remedies", en: University of Colorado Law Review (Vol. 57), pp. 720-721.

Marsal Guillamet, Joan, y Lauroba Lacasa, Elena (2003): "Mecanismos de protección en caso de incumplimiento contractual. Cumplimiento específico e indemnización por daños y perjuicios", en: Espiau, Santiago, y Vaquer, Antoni (editores), Bases de un Derecho contractual europeo (Valencia, Tirant lo Blanch), pp. 459-469.

Martin Pérez, José (1979): "Artículos 1.088 a 1.100", en: Albaladejo García, Manuel (director), Comentarios al Código Civil y Compilaciones Forales (Madrid, Revista de Derecho Privado), Vol. XV, tomo I, pp. 188-353..

Mazeaud, Henri; Mazeaud, Jean; Mazeaud, Leon, y Chabas, Francois (1997): Derecho civil, Obligaciones (Buenos Aires, Zavalía Editor), Vol. I.

Menezes Cordeiro, António (2005): Tratado de Direito civil portugués, $3^{\text {a }}$ edição, aumentada e inteiramente revista (Coimbra, Livraria Almedina), Vol. I.

Meza Barros, Ramón (1990): Manual de Derecho Civil, De las obligaciones (Santiago de Chile, Editorial Jurídica de Chile).

Miláns Del Bosch Portolés, Iván (2012): “Cumplimiento e incumplimiento del contrato internacional", en: O'callaghan Muñoz, Xavier (coordinador), Cumplimiento e incumplimiento del contrato (Madrid, Editorial Universitaria Ramón Areces), pp. 673-703. 
MösLEIN, Florian (2010): "Legal innovation in European contract law: within and beyond the (Draft) Common Frame of Reference", en: Micklitz, Hans, y Cafaggi, Fabrizio (editores), European Private Law after the Common Frame of Reference (Cheltenham, Edward Elgar Publishing Limited), pp. 173-219.

POSNER, Eric (2002): "Economic Analysis of Contract Law after Three Decades: Success or Failure?". Disponible en: http://www.law.uchicago.edu/publications [visitado el 12.07.2016].

Poveda Bernal, Margarita (2003): "Remedios ante situaciones contractuales anómalas", en: Vattier, Carlos; De la Cuesta, José, y Caballero, José (directores), Código Europeo de Contratos. Academia de lusprivatistas Europeos (Pavía) (Madrid, Dykinson), Vol. II, pp. 589-599.

Ramos, David (2012): "Derecho uniforme, interpretación uniforme y sus retos evolutivos. De la diversidad en las jurisdicciones a la diversidad en las transacciones y contextos comerciales", en: Revista de Derecho Mercantil (Vol. 286), pp. 93-150.

Rivera RestrePO, José (2017a): "La gravedad de incumplimiento como requisito del derecho de opción del acreedor. Tendencias modernas", en: RJUAM (Vol. 34), pp. 267-291.

Rivera Restrepo, José (2017b): "Marco Común de Referencia y derecho de opción del acreedor en el incumplimiento contractual", en: Revista Díkaion (Vol. 25, No 2), pp. 266-288.

(2017c): "Es necesaria la imputabilidad para que opere el derecho de opción del acreedor", en: Revista Boliviana de Derecho y Actualidad Jurídica Iberoamericana (Vol. 24), pp. 120-139.

(2017d): "El derecho de opción en Italia", en: Revista Direito GV (Vol. 13, No 1), pp. 303-333.

(2017e): "El derecho de opción del acreedor ante el Derecho alemán de las obligaciones. Tendencias modernas", en: Revista Jurídica (Vol. 14, $\mathrm{N}^{\circ} 1$ ), pp. 40-53.

(2016a): "El fundamento del derecho de opción del ante el incumplimiento contractual (condición resolutoria tácita)", en: Foro. Revista de Ciencias Jurídicas y Sociales. Nueva Época (Vol. 19, № 1), pp. 203-244.

(2016b): "Algunas observaciones acerca del derecho de opción del acreedor ante el incumplimiento contractual, en el common law", en: Cuadernos de Derecho Transnacional (Vol. 8, № 1), pp. 223-233.

(2016c): “ ¿Es necesaria la mora del deudor para que opere el derecho de opción del acreedor?", en: Revista Jurídica Cajamarca, Derecho y Cambio Social (Vol. 45), pp. 1-15. 
Rouiller, Nicolas (2007): Droit suisse des obligations et Principes du droit européen des contracts (Lausanne, Cedidac).

SánCHEZ LoRenzo, Sixto (2005): "La frustración del contrato en el derecho comparado y su incidencia en la contratación internacional", en: Revista de la Corte Española de Arbitraje (Vol. XX), pp. 45-88.

(2002): Derecho privado europeo (Granada, Comares).

San Miguel Pradera, Lis (2003): "La excesiva onerosidad: una propuesta de regulación europea", en: Espiau, Santiago, y Vaquer, Antoni (editores), Bases de un Derecho contractual europeo (Valencia, Tirant lo Blanch), pp. 371-384.

Schulze, Reiner (2009): "El Acquis Communautaire y el Marco Común de Referencia para el Derecho contractual europeo, Principios de Derecho contractual europeo y Principios de Unidroit sobre contratos comerciales internacionales", en: Ferrer, María Pilar, y Martínez, Anselmo (directores), Actas del Congreso Internacional celebrado en Palma de Mallorca, 26 y 27 de abril de 2007 (Madrid, Dykinson), pp. 51-61.

(2003): "El Derecho contractual europeo y sus textos básicos", en: Espiau, Santiago, y Vaquer, Antoni (editores), Bases de un Derecho contractual europeo (Valencia, Tirant lo Blanch), pp. 629-637.

SCHÄFER, Hans-Bernd, y Oтт, Claus (2004): The economic analysis of civil law (Massachusetts, Cheltenham, UK, Edward Elgar).

ShavelL, Steven (2004): Foundations of Economic Analysis of Law. USA (Cambridge, Massachusetts, The Belknap Press of Harvard University Press).

Ulen, Thomas (1984): "The efficeny of specific performance: Toward a unified theory of contract remedies", en: Michigan Law Review (Vol. 83, № 2), pp. 341-403.

UNIDROIT (2010): "Principios Unidroit sobre los contratos comerciales internacionales 2010". Disponibles en: https://www.unidroit.org/spanish/principles/ contracts/principles2010/blackletter2010-spanish.pdf y http://campus.usal. es/ derinfo/Material/LegOblContr/PECL\%20l+II.pdf.

Vattier Fuenzalida, Carlos (2008): "El Derecho europeo de contratos y el anteproyecto de Pavía", en: Anuario de Derecho civil (Vol. LXI, № IV), pp. 1841-1865.

(2003): "Capítulo XXI. El Anteproyecto de Pavía", en: Prats, Lorenzo; Palao, Guillermo, y Reyes, María José (coordinadores), Derecho Patrimonial europeo (Navarra, Thomson Reuters Aranzadi), pp. 419-436.

VÁzQuez LePINETTE, Tomás (1995): La conservación de las mercaderías en la compraventa internacional (Valencia, Tirant lo Blanch), pp. 175-176. 
Vicente Domingo, Elena (2003): "El resarcimiento de los daños", en: Vattier, Carlos; De La Cuesta, José, y Caballero, José (directores), Código Europeo de Contratos. Academia de lusprivatistas Europeos (Pavía) (Madrid, Dykinson), Vol. II, pp. 601-617.

VIDAl Olivares, Álvaro (2008): "La carga de mitigar las pérdidas del acreedor y su incidencia en el sistema de remedios por incumplimiento", en: Guzmán, Alejandro (editor), Estudios de Derecho Civil III (Santiago de Chile, LegalPublishing), pp. 429-457.

Vidal Olivares, Álvaro (2006): "El incumplimiento contractual y los remedios de que dispone el acreedor en la Compraventa Internacional", en: Revista Chilena de Derecho, (Vol. 33, No 3), pp. 468-469.

Vidal Olivares, Álvaro, y De la Maza Gazmurı, Íñigo (2014): “Propósito práctico, incumplimiento contractual y remedios del acreedor. Con ocasión de tres recientes sentencias de la Corte Suprema", en: Revista lus et Praxis (Vol. 20, $\left.\mathrm{N}^{\circ} 1\right)$, pp. 15-38.

Walz, Gustav (1943): "Esencia del derecho internacional y crítica de sus negadores", en: Revista de Derecho Privado (Vol. XXII).

WiCKER, Guillaume (2008): "Damages-indemnity", en: Fauvarque-Cosson, Bénédicte, y Mazeaud, Denis (editores), European Contract Law. Materials for a Common Frame of Reference: Terminology, guiding principles, Mole Rules (Munich, Sellier, European Law Publishers), pp. 275-317.

WhITTAKER, Simon (2006): "The Terminologies of Civil Protection: Rights, Remedies and Procedures", en: Pozzo, Bárbara, y Jacometti, Valentina (editoras), Multilingualism and the Harmonisation of European Law (Alphen aan den Rijn, Kluwer Law Internacional), pp. 45-60.

Yzquierdo Tolsada, Mariano (2003): "Consecuencias del incumplimiento. En particular, reflexiones sobre los remedios solutorios por el equivalente, los remedios resarcitorios y ciertas medidas de presión sobre el deudor incumplidor", en: Vattier, Carlos; De La Cuesta, José, y Caballero, José (directores), Código Europeo de Contratos. Academia de lusprivatistas Europeos (Pavía) (Madrid, Dykinson), Vol. II, pp. 435-451.

Zimmermann, Reinhard (2000): Estudios de Derecho Privado Europeo (Madrid, Civitas). 